\title{
PPAR $\gamma$
}

The Intrinsic Negative Regulator of HIV-1 Replication

Transcriptional profiling reveals molecular signatures associated with HIV permissiveness in Th1Th17 cells and identifies Peroxisome Proliferator-Activated Receptor Gamma as an intrinsic negative regulator of viral replication

Bernier et al. 


\title{
Transcriptional profiling reveals molecular
} signatures associated with HIV permissiveness in Th1Th17 cells and identifies Peroxisome Proliferator-Activated Receptor Gamma as an intrinsic negative regulator of viral replication

\author{
Annie Bernier ${ }^{1,2+}$, Aurélie Cleret-Buhot ${ }^{1,2+}$, Yuwei Zhang ${ }^{1,2 \dagger}$, Jean-Philippe Goulet ${ }^{3,4}$, Patricia Monteiro ${ }^{1,2}$,
} Annie Gosselin', Sandrina DaFonseca 1,2, Vanessa Sue Wacleche ${ }^{1,2}$, Mohammad-Ali Jenabian ${ }^{5,6}$, Jean-Pierre Routy ${ }^{5,6,7}$, Cécile Tremblay ${ }^{1,2}$ and Petronela Ancuta ${ }^{1,2^{*}}$

\begin{abstract}
Background: We previously demonstrated that primary Th1Th17 cells are highly permissive to HIV-1, whereas Th1 cells are relatively resistant. Molecular mechanisms underlying these differences remain unknown.

Results: Exposure to replication competent and single-round VSV-G pseudotyped HIV strains provide evidence that superior HIV replication in Th1Th17 vs. Th1 cells was regulated by mechanisms located at entry and post-entry levels. Genome-wide transcriptional profiling identified transcripts upregulated $(n=264)$ and downregulated $(n=235)$ in Th1Th17 vs. Th1 cells ( $p$-value < 0.05; fold change cut-off 1.3). Gene Set Enrichment Analysis revealed pathways enriched in Th1Th17 (nuclear receptors, trafficking, p38/MAPK, NF-KB, p53/Ras, IL-23) vs. Th1 cells (proteasome, interferon $\alpha / \beta$ ). Differentially expressed genes were classified into biological categories using Gene Ontology. Th1Th17 cells expressed typical Th17 markers (IL-17A/F, IL-22, CCL20, RORC, IL-26, IL-23R, CCR6) and transcripts functionally linked to regulating cell trafficking (CEACAM1, MCAM), activation (CD28, CD40LG, TNFSF13B, TNFSF25, PTPN13, MAP3K4, LTB, CTSH), transcription (PPARY, RUNX1, ATF5, ARNTL), apoptosis (FASLG), and HIV infection (CXCR6, FURIN). Differential expression of CXCR6, PPARY, ARNTL, PTPN13, MAP3K4, CTSH, SERPINB6, PTK2, and ISG20 was validated by RT-PCR, flow cytometry and/or confocal microscopy. The nuclear receptor PPARY was preferentially expressed by Th1Th17 cells. PPARY RNA interference significantly increased HIV replication at levels post-entry and prior HIV-DNA integration. Finally, the activation of PPARY pathway via the agonist Rosiglitazone induced the nuclear translocation of PPARY and a robust inhibition of viral replication.
\end{abstract}

Conclusions: Thus, transcriptional profiling in Th1Th17 vs. Th1 cells demonstrated that HIV permissiveness is associated with a superior state of cellular activation and limited antiviral properties and identified PPARY as an intrinsic negative regulator of viral replication. Therefore, triggering PPARY pathway via non-toxic agonists may contribute to limiting covert HIV replication and disease progression during antiretroviral treatment.

Keywords: HIV, CD4 ${ }^{+}$T-cells, Th1Th17, Th1, cDNA microarrays, PPARY

\footnotetext{
*Correspondence: petronela.ancuta@umontreal.ca

${ }^{\dagger}$ Equal contributors

'Department of Microbiology, Infectiology, and Immunology, Université de

Montréal, Faculty of Medicine, Montreal, Quebec, Canada

${ }^{2}$ CHUM-Research Centre, 900 rue Saint-Denis, Tour Viger, room R09.416,

Montréal, Quebec H2X 0A9, Canada

Full list of author information is available at the end of the article
} 


\section{Background}

Despite the success of current antiretroviral therapies (ART), persistence of HIV-1 reservoirs represents a major barrier against viral eradication [1-4]. CD4 ${ }^{+} \mathrm{T}$-cells are key players for antiviral immunity [5] but also main targets for productive HIV infection and long-term persistence $[3,6]$. The discovery of new molecular mechanisms underlying the ability of HIV to select its targets and the identification of new therapeutic strategies to block this process represent an open field of investigations in the framework of current efforts toward HIV eradication [2]. The status of HIV permissiveness in a given cell subset is dependent in part on virus ability to counteract intrinsic cellular defenses mechanisms [7] mediated by several restriction factors including APOBEC3G [8-10], TRIM5 $\alpha[11,12]$, Tetherin/ CD317 [13] and most recently discovered, SAMHD1 $[14,15]$. In addition to restriction factors that directly target the virus, p21/CDKN1A, a potent inhibitor of cyclin dependent kinases, was demonstrated to limit HIV replication in macrophages [16] and CD4 ${ }^{+}$T-cells from HIV elite controllers $[17,18]$, likely by an indirect mechanism. On the other hand, HIV uses the host-cell machinery for its successful replication. The receptor CD4 and coreceptors CCR5 and CXCR4 were the first HIV-dependency factors (HDFs) described for HIV entry [19,20]. Several other HDFs acting at post-entry levels were identified in the last years using genome-wide RNA interference screenings in HeLa [21,22], $293 \mathrm{~T}$ [23] and Jurkat cell lines [24] and other high throughput techniques [25]. These studies revealed large lists of HDFs with very limited overlap when transcripts were analyzed individually [25,26]. However, when HDFs identified in each screen were functionally classified using gene ontology (GO), a greater level of overlap was observed for processes such as Nuclear pore/ transport, DNA-Repair, Ubiquitin-associated/Proteasome, Mediator Complex/Transcription, RNA binding, GTP Binding, and Helicase [25]. The NF- $\mathrm{kB}$, peroxisome proliferator-activated receptor (PPAR), and retinoic acid receptor (RAR) activation pathways were identified as being critical in two studies $[21,24]$. Nevertheless, some well known permissiveness factors (e.g., cyclophilin A, LEDGF/ p75) were not identified in these screens [25], suggesting that many other factors important for HIV permissiveness remain to be identified, especially in primary $\mathrm{CD} 4^{+} \mathrm{T}$-cells.

The chemokine receptors CXCR3, CCR4, and CCR6 are markers for memory $\mathrm{CD} 4^{+} \mathrm{T}$-cells subsets with distinct polarization potential, antigenic specificity, and permissiveness to HIV $[27,28]$. CXCR3 ${ }^{+}$CCR4 ${ }^{-}$CCR6 $^{+}$T-cells exhibit a Th1Th17 polarization profile as they express transcription factors and produce cytokines specific for both Th1 (T-bet and IFN- $\gamma$ ) and Th17 (RORC and IL-17) lineages, while CXCR $^{+}{ }^{+}$CR $44^{-C C R} 6^{-}$T-cells express functional markers specific for the Th1 lineage only [29,30]. In addition, $\mathrm{CXCR}^{+}{ }^{+} \mathrm{CCR}^{-} \mathrm{CCR}^{+} / \mathrm{Th} 1 \mathrm{Th} 17$ cells are specific to pathogens such as $M$. tuberculosis and C. albicans, while $\mathrm{CXCR}^{+}{ }^{+} \mathrm{CCR} 4^{-} \mathrm{CCR}^{-} / \mathrm{Th} 1$ cells proliferate in response to CMV $[29,30]$. We previously reported that: (i) Th1Th17 cells are highly permissive to replication-competent R5 and X4 HIV strains, while Th1 cells are relatively resistant; (ii) $\mathrm{CCR6}^{+}$T-cells (including Th1Th17 cells) are major cellular targets of infection in vivo; and that (iii) the frequency of Th1Th17 but not Th1 cells is dramatically reduced in HIV-infected subjects vs. uninfected controls, with viral suppressive ART being inefficient in restoring Th1Th17 paucity [31]. Distinct HIV replication in Th1Th17 vs. Th1 cells is consistent with findings by other groups that CMV-specific but not M. tuberculosis-specific cells are protected from HIV infection by an autocrine production of CCR5 binding chemokines [32,33]. Differences in HIV permissiveness between Th1Th17 and Th1 cells may account for the depletion of $M$. tuberculosis-specific cells [34] and the deleterious consequences of CMV-specific cell persistence in HIV-infected subjects [35]. Although Th1Th17 and Th1 cells produce similar CCL3 and CCL5 levels, a superior CCR5 expression on Th1Th17 cells ex vivo argue in favor of their increased ability to support R5 HIV entry [31]. However, the expression of CXCR4 was similar on Th1Th17 and Th1 cells despite the fact that permissiveness to X4 HIV strains is restricted to Th1Th17 cells [31], suggesting the possibility that additional postentry mechanisms likely regulate HIV replication in Th1 cells. Indeed, a very recent study demonstrated that HIV restriction in CMV-specific cells (Th1 polarized) is mediated by post-entry antiviral mechanisms linked to type-I IFN responses and the selective expression of TRIM22 and TRIM5 restriction factors [36]. Thus, understanding molecular differences between Th1Th17 and Th1 cells may provide new insights into molecular mechanisms of HIV permissiveness $v s$. restriction in primary $\mathrm{CD} 4^{+} \mathrm{T}$-cell subsets and reveal new therapeutic avenues.

In this study we aimed to identify molecular mechanisms underlying differences in HIV permissiveness between HIV-permissive Th1Th17 and HIV-resistant Th1 cells. This study provides a unique genome-wide characterization of differential gene expression in Th1Th17 vs. Th1 cells, reveals pathways and biological functions linked to HIV permissiveness, and identifies the PPARY activation pathway as the "Achilles' heel" for HIV permissiveness that may be therapeutically targeted to limit viral replication in primary $\mathrm{CD} 4^{+} \mathrm{T}$-cells.

\section{Results}

Superior HIV permissiveness in Th1Th17 vs. Th1 cells upon exposure to replication-competent and single-round viruses The increased expression of CCR 5 on Th1Th17 vs. Th1 cells [31] suggests a superior ability of Th1Th17 cells to support HIV entry. To distinguish between entry and post-entry regulation mechanisms, HIV integration in 
Th1Th17 and Th1 cells was quantified upon exposure to replication competent R5 HIV strain (NL4.3BAL-GFP) or single-round VSV-G-pseudotyped HIV (HIV-VSVG-GFP) that enters cells independently of the HIV receptor CD4 and coreceptors CCR5 and CXCR4 [37,38]. To this aim, highly pure matched Th1Th17 and Th1 subsets were sorted by flow cytometry from four different donors (Additional file 1: Figure S1), stimulated via $\mathrm{CD} 3 / \mathrm{CD} 28$ for 3 days, and exposed to HIV (Figure 1A). HIV-DNA integration in Th1Th17 vs. Th1 cells was significantly higher when cells were exposed to NL4.3BAL-GFP (Figure 1B), similar to our previous findings [31]. Differences were marginally significant when cells were exposed to HIV-VSVG-GFP (Figure 1C). Levels of GFP-expression, an indicator of HIV transcription, were slightly higher in Th1Th17 vs. Th1 cells, with donor-to-donor variations being observed
(Figure 1D). Because the stage of cells differentiation may be linked to HIV permissiveness, we investigated the central memory $\left(\mathrm{CM}, \mathrm{CD} 45 \mathrm{RA}^{-} \mathrm{CCR} 7^{+}\right) v s$. effector memory (EM, CD45RA ${ }^{-} \mathrm{CCR}^{-}$) phenotype in Th1Th17 and Th1 subsets, using previously described markers $[6,39,40]$. No significant differences were found between Th1Th17 and Th1 subsets in terms of CM/EM ratios (data not shown). In addition, similar differences were observed in HIV permissiveness between Th1Th17 and Th1 cells when infection was performed on sorted CM and EM subsets (data not shown). These results provide evidence that HIV permissiveness in memory Th1Th17 vs. Th1 cells is mainly regulated at the entry level; however, post-entry mechanisms located at the pre- and/or post-integration level likely contribute to these differences.

A
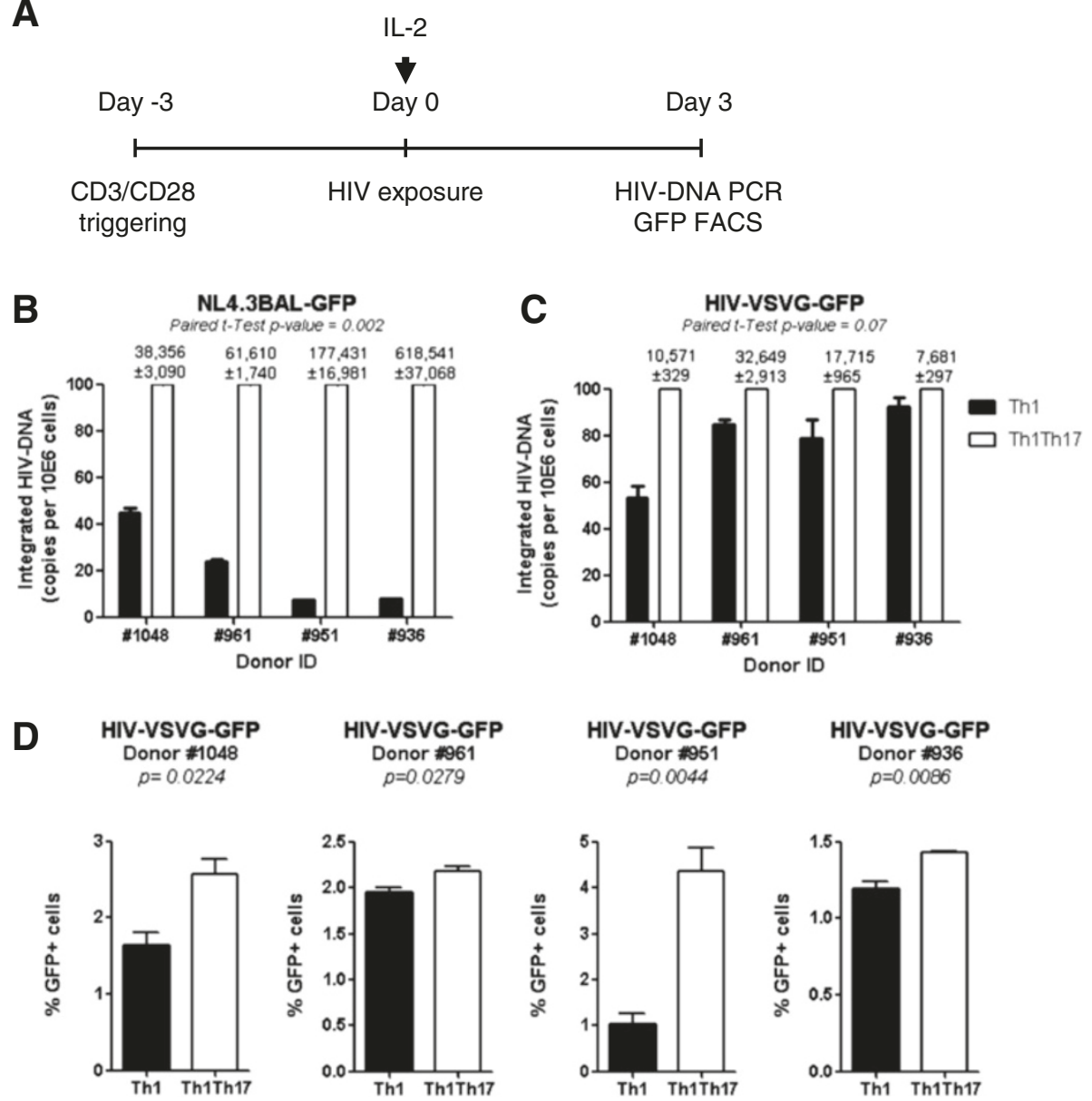

Figure 1 Superior HIV replication in Th1Th17 vs. Th1 cells is regulated at entry and post-entry level. Matched Th1 and Th1Th17 cells were sorted by flow cytometry from four different HIV-uninfected subjects and stimulated via CD3/CD28 for 3 days (A). Cells were exposed to replication competent NL4.3BAL-GFP (B) or single round HIV-VSVG-GFP pseudotyped strains (50 ng HIV-p24/10 $0^{6}$ cells) (C-D) for 3 h at $37^{\circ} \mathrm{C}$. Unbound virus was removed by extensive washing, and cells were cultured for 3 additional days in the presence of IL-2 (5 ng/ml). Integrated HIV-DNA and GFP expression levels were quantified by nested real-time PCR (B-C) and flow cytometry (D), respectively, at day 3 post-infection. Shown in $\mathbf{B}-\mathbf{C}$ is relative HIV-DNA integration in Th1 vs. Th1Th17 cells (normalized to the maximal value considered to be $100 \%$ in Th1Th17 cells); values above graphs are integrated HIV-DNA copies per $10^{6}$ cells in Th1Th17 cells (mean \pm SD of triplicate wells). Paired $t$-Test values are indicated on the graphs. 
Distinct gene expression profiles in Th1Th17 vs. Th1 cells To identify transcriptional signatures associated with HIV permissiveness and resistance in Th1Th17 and Th1 cells, respectively, we used the Affymetrix technology (Gene Chip ${ }^{\oplus}$ Human Genome U133 Plus 2.0 Array) for a genome-wide transcriptional analysis in matched Th1Th17 and Th1 cells isolated from the peripheral blood of four uninfected individuals and stimulated via CD3/CD28 for 3 days in vitro. The choice of this timing is justified by the fact that robust differences in HIV permissiveness between Th1Th17 vs. Th1 cells were observed in our previous studies when cells were exposed to the virus at day 3 post TCR triggering [31]. The primary analysis revealed 38,113 present calls, with 780 probe sets that were differentially expressed in Th1Th17 vs. Th1 cells (one-way ANOVA p-value <0.05): 438 probe sets upregulated (corresponding to 392 known genes and 46 unknown transcripts) and 342 downregulated (corresponding to 268 known genes and 74 unknown transcripts) (Figure 2A-B; Additional file 2: Table S1 and Additional file 3: Table S2). Further, 265 and 235 probe sets were upregulated and downregulated, respectively, in Th1Th17 vs. Th1 subsets with a fold change (FC) superior to 1.3 (Figure 2C-D; Additional file 2: Table S1 and Additional file 3: Table S2). Transcripts upregulated in Th1Th17 vs. Th1 cells (p-value $<0.05$, FC cut-off 1.3) include known markers of Th17 cells such as IL-17A, IL-22, CCL20, IL-17 F, RORC, IL-26, IL-23R, CCR6, IL1R1, and CSF2/GM-CSF (Table 1). When the adjusted p-value (adj. p-value <0.05) was calculated, two Th17-specific genes were identified as being highly expressed in Th1Th17 vs. Th1 subsets: the transcription factor RORC and the cytokine IL-22 (Additional file 2: Table S1). These findings provide a first validation of the transcriptional results obtained by microarray studies. In addition, the analysis of top differentially expressed genes reveals new markers for Th1Th17 cells including CTSH, PTPN13, CXCR6, MCAM, CCR2, PPAR $\gamma$, TNFSF13B, ARNTL, FURIN, MAP3K4, and CEACAM1 (Table 1) and for Th1 cells including CXCL10, PTK2, CXCR5, PECAM1, CCL17, ALCAM, and GRK5 (Table 2). Thus, Th1Th17 and Th1 cells distinguish from each other by a set of transcripts (corresponding to 660 known genes and 120 unknown transcripts) that may be involved in the differential regulation of HIV permissiveness $v s$. restriction in these cells.

\section{Gene Set Enrichment Analysis (GSEA)}

To identify biological processes differentially regulated in Th1Th17 vs. Th1 cells upon CD3/CD28 triggering, Gene Set Enrichment Analysis (GSEA), a knowledge based approach for interpreting genome-wide expression data [41], was conducted from the expression levels of all the probes detected. Normalized enrichment scores (NES), nominal p-values, and false discovery rates (FDR) were analyzed to systematically test three categories of gene sets from the Molecular Signatures Database (MSigDB) of the Broad Institute (Boston, MA, USA): Canonical pathways (C2), Transcription factors (C3), and Gene Ontology (C5). Among canonical pathways differentially expressed in Th1Th17 vs. Th1 cells $($ FDR $<0.05)$, GSEA revealed a significant enrichment in pathways including ERK-transactivationcytoskeletal-MAPK-JNK, Nuclear receptor/transcription (RORC, RORA, PPAR $\gamma$, PPAR $\alpha$ ), Circadian clock (ARNTL), leukocyte transendothelial migration, Cytokine/cytokine receptor interactions (IL-22, CCL20, IL-23R, IL-26, IL-17, CCR6, CXCR6, IL-1R1, TNFSF25, TNFSF13B, CCR2), MAPK signaling (MAP3K4, IL-1R1), p38/MAPK, IL-23, and BMAL1/CLOCK (ARNTL) (Additional file 4: Figure S2A, left panel), while gene sets including those linked to Interferon $\alpha / \beta$ signaling (IFI27, IRF8, ISG20, MX2, IFIT3, IRF9, IRF7) and proteasome (Additional file 4: Figure S2A, right panel) were found downregulated in Th1Th17 vs. Th1 cells. Moreover, GSEA identified that gene sets regulated by transcription factors including RORA, Oct-1, FOXO4, SMAD4, p53, FOXO1, AP1, and NF-кB were enriched in Th1Th17 vs. Th1 cells (Additional file 4: Figure S2B). Furthermore, GSEA revealed that biological functions including those linked to Cell adhesion, Enzyme-linked receptor protein signaling, and Receptor signaling/protein threonine kinase activity were enriched in Th1Th17 vs. Th1 cells, while pathways linked to different catabolic processes were downregulated (Additional file 4: Figure S2C). Together, these GSEA results point to major functional differences between Th1Th17 and Th1 cells, with Th1Th17 cells exhibiting a distinct trafficking potential and a state of superior metabolic activation, under the control of specific transcription factors such as $\mathrm{p} 53, \mathrm{AP}-1$ and NF-kB, which are known key regulators of HIV replication [21,24,42]. These features, together with a decreased proteasomal activity and interferon signaling and reduced levels of the IFN-induced antiviral factors ISG20 [43], may explain preferential HIV replication in Th1Th17 vs. Th1 cells.

\section{Gene Ontology (GO) classification by biological functions of differentially expressed genes}

To extract further meaning, the differentially expressed genes in Th1Th17 vs. Th1 cells $(\mathrm{p}<0.05$, cut-off 1.3 -fold) were classified into 13 biological functions using GO (Figure 3).

\section{Adhesion molecules, cytokines, and chemokines}

Genes upregulated in Th1Th17 vs. Th1 included the adhesion molecules MCAM (Melanoma Cell Adhesion Molecule) and CEACAM1 (Carcinoembryonic Antigen cellular Adhesion Molecule 1); the chemokine receptors CCR6, CCR2, and CXCR6; the cytokine receptors IL-1R1 and IL-12RB1 (suggested role in the differentiation and/or proliferation of IL-17 producing cells [44]); and the mRNA 
A

Present calls $(n=38,113)$

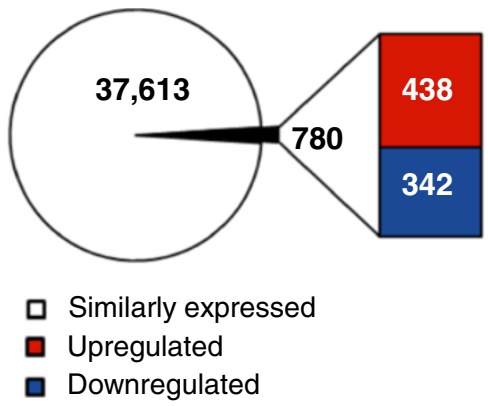

B $\quad p$-value $<0.05(n=780)$

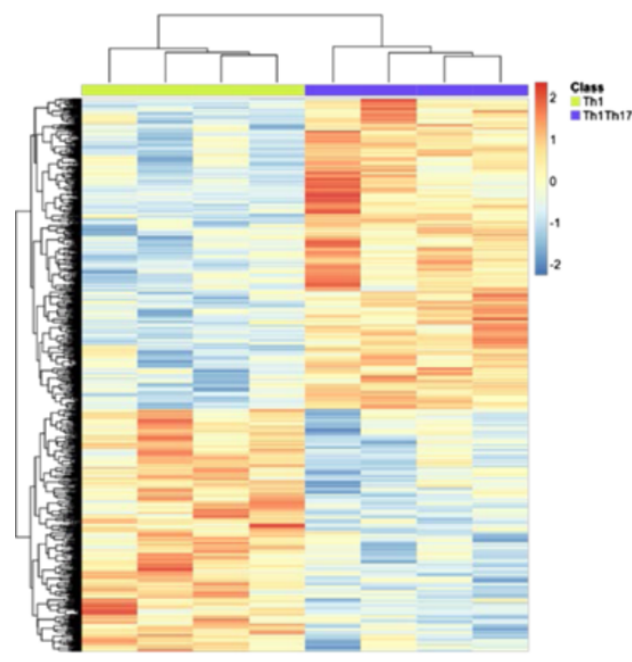

C $\quad$-value $<0.05$

FC cutoff 1,3

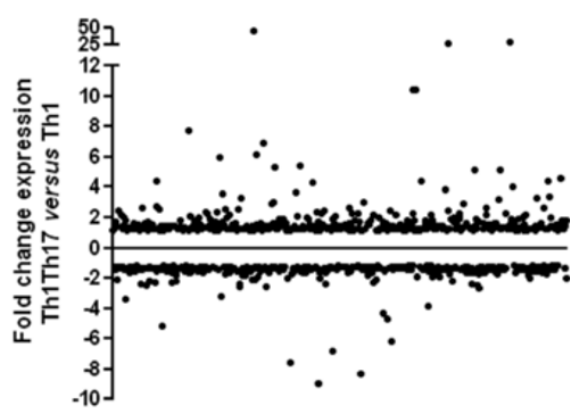

D p-value/Adj. p-value $<0.05$

FC cutoff 1.3

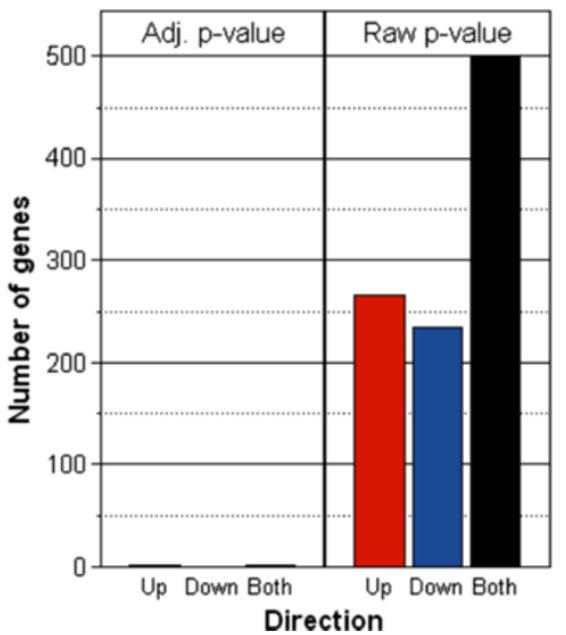

Figure 2 Identification of differentially expressed genes in Th1Th17 vs. Th1 cells. Matched Th1Th17 and Th1 subsets from four HIV-uninfected donors were sorted and stimulated as in Figure 1. Total RNA was extracted and reverse transcribed into CDNA that was then hybridized on the Human Genome U133 Plus 2.0 Array (Affymetrix). Statistical analysis using one-way ANOVA was performed to identify differentially expressed genes ( $p$-value $<0.05$ ) and the differential expression fold change $(F C)$ was calculated. (A) Shown is a schematic representation of the number of "present calls" shared $(n=38,113)$ and differentially expressed $(n=438$ upregulated and $n=342$ downregulated) in Th1Th17 vs. Th1 ( $p$-value $<0.05)$. (B) Hierarchical clustering analysis of differentially expressed probe sets separated the 8 samples in two groups corresponding to Th1Th17 and Th1 subsets. (C) Depicted is the fold change of differentially expressed genes in Th1Th17 vs. Th1 ( $p$-value $<0.05$ and FC cut off 1.3). (D) Shown are numbers of probe sets differentially expressed in Th1Th17 vs. Th1 with a fold change cut-off of 1.3 according to their $p$-value $(n=265$ upregulated in red and $n=235$ downregulated in blue) or adjusted $p$-value ( $n=2$ upregulated).

for cytokines such as IL-2, IL-15, IL-17A, IL-17 F, IL-22, IL-26, CCL20, lymphotoxin beta (LTB), TNFRSF13B (TNF superfamily member B cell-activating factor (BAFF) or B-lymphocyte stimulator (Blys)), and CSF2/GM-CSF (Figure 3A-B; Table 1; Additional file 2: Table S1). Genes upregulated in Th1 vs. Th1Th17 cells included those encoding for the adhesion molecules ALCAM (Activated Leukocyte Cell Adhesion Molecule), PECAM-1 (Platelet Endothelial Cell Adhesion Molecule 1), CDH1 (cadherin1/E-cadherin, a ligand for KLRG1), and CADM1 (CellAdhesion Molecule 1); the surface antigen Thy-1, protein tyrosine kinase 2 (PTK2/FAK); the chemokine receptor CXCR5; the chemokines CCL17, CXCL10, and XCL1/ lymphotactin; and the cytokines IL-5 and IL-4 (Figure 3A-B;
Table 2; Additional file 3: Table S2). Thus, in addition to their Th1 polarization profile reflected by the expression of the Th1-specific transcription factor T-bet and the production of IFN- $\gamma$ [31], the pool of $\mathrm{CXCR}^{+}{ }^{+} \mathrm{CCR} 6^{-}$T-cells includes subsets that share phenotypic and functional properties with Tfh and Th2 cells. However, levels of IL-5 production and GATA3 expression are significantly lower compared to CCR4 $4^{+} \mathrm{CCR} 6^{-} \mathrm{Th} 2$ cells [31], suggesting that the frequency of Th2 cells within the $\mathrm{CXCR}^{+} \mathrm{CCR}^{-}$ fraction is relatively low. Together these results reveal distinct molecular mechanisms involved in the regulation of tissue-specific trafficking for Th1Th17 (via MCAM, CEACAM1, CCR2, CXCR6) and Th1 cells (via ALCAM, PECAM-1, CDH1, CADM1, and CXCR5) that may be 
Table 1 Selected genes upregulated in Th1Th17 vs. Th1

\begin{tabular}{lccl}
\hline $\begin{array}{l}\text { Gene } \\
\text { symbol }\end{array}$ & $\begin{array}{c}\text { Fold change } \\
\text { Th1Th17/Th1 }\end{array}$ & p-value & Gene title \\
\hline IL17A & 44,94 & 0,000 & Interleukin 17A
\end{tabular}

\section{IL22}

CCL20

29,18

\section{0,000}

Interleukin 22

\section{IL17F}

RORC

IL26

IL23R

$\mathrm{CTSH}$

CCR6

HPGD

PTPN13

KLRB1

IL1R1

CSF2

LST1

CXCR6

MCAM

CCR2

RORA

CD80

IL18RAP

PPARG

TNFRSF25

$$
2,01
$$

TNFSF13B

ARNTL

\section{IL15}

FURIN

IL12RB1

ATF5

THY1

MAP3K4
26,69

10,47

7,73

6,90

6,14

5,46

5,38

5,16

4,45

3,87

3,39

2,68

2,60

2,44

2,27

2,25

2,14

2,08

2,05

2,04

1,87

1,72

1,69

1,61

1,56

1,54

1,54

1,53
0,000

Chemokine (C-C motif) ligand 20

0,039 Interleukin $17 \mathrm{~F}$

0,000

0,000

0,000

0,000

0,001

0,004

0,000

0,040

0,004

0,041

0,001

0,003

0,001

0,034

0,005

0,013

0,049

0,019

0,008

0,014

0,012

0,024

0,012

0,040

0,031

0,004

0,043

0,003
RAR-related orphan receptor $C$

Interleukin 26

Interleukin 23 receptor

Cathepsin $\mathrm{H}$

Chemokine (C-C motif) receptor 6

Hydroxyprostaglandin dehydrogenase 15-(NAD)

Protein tyrosine phosphatase, non-receptor type 13

Killer cell lectin-like receptor subfamily B, member 1

Interleukin 1 receptor, type I

Colony stimulating factor 2 (granulocyte-macrophage)

Leukocyte specific transcript 1

Chemokine (C-X-C motif) receptor 6

Melanoma cell adhesion molecule

Chemokine (C-C motif) receptor 2

RAR-related orphan receptor A

CD80 molecule

Interleukin 18 receptor accessory protein

Peroxisome proliferator-activated receptor gamma

Tumor necrosis factor receptor superfamily, member 25

Tumor necrosis factor (ligand) superfamily, member 13b

Lymphotoxin beta (TNF superfamily, member 3)

Aryl hydrocarbon receptor nuclear translocator-like

\section{Interleukin 15}

Furin (paired basic amino acid

\section{Interleukin 12 receptor, beta 1}

Activating transcription factor 5

Thy-1 cell surface antigen kinase kinase kinase 4 cleaving enzyme)

Mitogen-activated protein
Table 1 Selected genes upregulated in Th1Th17 vs. Th1 (Continued)

\begin{tabular}{|c|c|c|c|}
\hline CEACAM1 & 1,52 & 0,021 & $\begin{array}{l}\text { Carcinoembryonic antigen- } \\
\text { related cell adhesion molecule } 1\end{array}$ \\
\hline MAP3K4 & 1,52 & 0,006 & $\begin{array}{l}\text { Mitogen-activated protein } \\
\text { kinase kinase kinase } 4\end{array}$ \\
\hline IL2 & 1,51 & 0,041 & Interleukin 2 \\
\hline ATF5 & 1,46 & 0,018 & $\begin{array}{l}\text { Activating transcription } \\
\text { factor } 5\end{array}$ \\
\hline CTSC & 1,43 & 0,023 & Cathepsin C \\
\hline CD40LG & 1,45 & 0,037 & CD40 ligand \\
\hline RUNX1 & 1,40 & 0,012 & $\begin{array}{l}\text { Runt-related transcription } \\
\text { factor } 1\end{array}$ \\
\hline PTEN & 1.39 & 0.031 & $\begin{array}{l}\text { Phosphatase and tensin } \\
\text { homolog }\end{array}$ \\
\hline CD28 & 1,37 & 0,046 & CD28 molecule \\
\hline TRIM8 & 1,36 & 0,011 & Tripartite motif-containing 8 \\
\hline CASP4 & 1,34 & 0,025 & $\begin{array}{l}\text { Caspase 4, apoptosis-related } \\
\text { cysteine peptidase }\end{array}$ \\
\hline CYP27B1 & 1,33 & 0,031 & $\begin{array}{l}\text { Cytochrome P450, family 27, } \\
\text { subfamily B, polypeptide } 1\end{array}$ \\
\hline FASLG & 1,33 & 0,046 & $\begin{array}{l}\text { Fas ligand (TNF superfamily, } \\
\text { member 6) }\end{array}$ \\
\hline
\end{tabular}

Shown are 44 differentially expressed genes ( $p$-value $<0.05$ and cut-off 1.3 fold) that are preferentially expressed in Th1Th17 vs. Th1 cells.

linked to the distinct in situ localization and contribution of these subsets to HIV pathogenesis.

\section{Immune responses and inflammation}

Th1Th17 cells express higher levels of transcripts corresponding to the costimulatory molecules CD28, CD40 ligand (CD40LG/CD154), FAS ligand (FASLG), the cytokines IL-2 and IL-15, LST1 (leukocyte specific transcript 1 , a regulator of cell motility [45]), the cytokines receptor IL23R (whose ligand IL-23 is involved in the stabilization of Th17 polarization [46] and the induction of pathogenic Th17 cells [47]), and the IL-18 receptor accessory protein (IL18RAP) (Figure 3C-D, Additional file 2: Table S1). In contrast, Th1 vs. Th1Th17 cells expressed superior RNA levels corresponding to the chemokines CCL17, CXCL10, XCL1 and the cytokines IL-5 and IL-4 (Figure 3C-D, Additional file 3: Table S2). Thus, Th1Th17 vs. Th1 cells appear to be more susceptible to activation, cell proliferation, and apoptosis, and also prone to respond to IL-23 for the maintenance of their Th17 differentiation and pathogenic potential.

\section{Transcription and cell differentiation}

Genes expressed at higher levels in cells corresponding to the Th1Th17 profile include the costimulatory molecule CD80, the receptors for TGF- $\beta$, TGFBR1 and TGFBR2, the Th17-specific transcription factors RORC and RORA [48,49], RUNX1 (runt-related transcription factor 1), the 
Table 2 Selected genes downregulated in Th1Th17 vs. Th1

\begin{tabular}{|c|c|c|c|}
\hline $\begin{array}{l}\text { Gene } \\
\text { symbol }\end{array}$ & $\begin{array}{l}\text { Fold change } \\
\text { Th1Th17/Th1 }\end{array}$ & p-value & Gene title \\
\hline $\mathrm{XCL} 1$ & $-7,53$ & 0,001 & Chemokine ( $\mathrm{C}$ motif) ligand 1 \\
\hline IL5 & $-3,35$ & 0,010 & $\begin{array}{l}\text { Interleukin } 5 \text { (colony-stimulating } \\
\text { factor, eosinophil) }\end{array}$ \\
\hline KLRK1 & $-2,66$ & 0,003 & $\begin{array}{l}\text { Killer cell lectin-like receptor } \\
\text { subfamily } K \text {, member } 1\end{array}$ \\
\hline LAIR2 & $-2,57$ & 0,004 & $\begin{array}{l}\text { Leukocyte-associated } \\
\text { immunoglobulin-like receptor } 2\end{array}$ \\
\hline IL4 & $-2,47$ & 0,013 & Interleukin 4 \\
\hline TIGIT & $-2,36$ & 0,001 & $\begin{array}{l}\text { T cell immunoreceptor with } \\
\text { Ig and ITIM domains }\end{array}$ \\
\hline $\mathrm{CDH} 1$ & $-2,35$ & 0,000 & $\begin{array}{l}\text { Cadherin 1, type 1, E-cadherin } \\
\text { (epithelial) }\end{array}$ \\
\hline IL17RB & $-2,33$ & 0,005 & Interleukin 17 receptor B \\
\hline CXCL10 & $-2,31$ & 0,046 & $\begin{array}{l}\text { Chemokine (C-X-C motif) } \\
\text { ligand } 10\end{array}$ \\
\hline FCRL3 & $-2,30$ & 0,048 & Fc receptor-like 3 \\
\hline IL-17RB & $-2,19$ & 0,003 & Interleukin 17 receptor B \\
\hline SLAMF7 & $-2,08$ & 0,027 & SLAM family member 7 \\
\hline PTK2 & $-2,01$ & 0,000 & PTK2 protein tyrosine kinase 2 \\
\hline CXCR5 & $-2,00$ & 0,013 & $\begin{array}{l}\text { Chemokine (C-X-C motif) } \\
\text { receptor } 5\end{array}$ \\
\hline ZNF80 & $-1,96$ & 0,008 & Zinc finger protein 80 \\
\hline CADM1 & $-1,89$ & 0,037 & Cell adhesion molecule 1 \\
\hline CD109 & $-1,84$ & 0,034 & CD109 molecule \\
\hline SERPINB6 & $-1,80$ & 0,003 & $\begin{array}{l}\text { Serpin peptidase inhibitor, } \\
\text { clade B, member } 6\end{array}$ \\
\hline PECAM1 & $-1,76$ & 0,004 & $\begin{array}{l}\text { Platelet/endothelial cell } \\
\text { adhesion molecule }\end{array}$ \\
\hline NFIA & $-1,64$ & 0,009 & Nuclear factor I/A \\
\hline TIAM2 & $-1,64$ & 0,008 & $\begin{array}{l}\text { T-cell lymphoma invasion and } \\
\text { metastasis } 2\end{array}$ \\
\hline BCL2L14 & $-1,63$ & 0,032 & BCL2-like 14 (apoptosis facilitator) \\
\hline ACPL2 & $-1,58$ & 0,013 & Acid phosphatase-like 2 \\
\hline$|F| 27$ & $-1,57$ & 0,026 & $\begin{array}{l}\text { Interferon, alpha-inducible } \\
\text { protein } 27\end{array}$ \\
\hline CCL17 & $-1,54$ & 0,019 & Chemokine (C-C motif) ligand 17 \\
\hline ALCAM & $-1,54$ & 0,009 & $\begin{array}{l}\text { Activated leukocyte cell adhesion } \\
\text { molecule }\end{array}$ \\
\hline H1F0 & $-1,50$ & 0,020 & $\mathrm{H} 1$ histone family, member 0 \\
\hline PLA2G4A & $-1,49$ & 0,030 & Phospholipase A2, group IVA \\
\hline HTATIP2 & $-1,49$ & 0,034 & $\begin{array}{l}\text { HIV-1 Tat interactive protein 2, } \\
30 \mathrm{kDa}\end{array}$ \\
\hline SMAD2 & $-1,48$ & 0,027 & SMAD family member 2 \\
\hline ISYNA1 & $-1,48$ & 0,026 & Inositol-3-phosphate synthase 1 \\
\hline ZNF827 & $-1,47$ & 0,030 & Zinc finger protein 827 \\
\hline TAF15 & $-1,47$ & 0,040 & $\begin{array}{l}\text { TBP-associated factor RNA } \\
\text { polymerase II }\end{array}$ \\
\hline GATA3 & $-1,46$ & 0,015 & GATA binding protein 3 \\
\hline
\end{tabular}

Table 2 Selected genes downregulated in Th1Th17 vs. Th1 (Continued)

\begin{tabular}{|c|c|c|c|}
\hline HLA-DOA & $-1,42$ & 0,032 & $\begin{array}{l}\text { Major histocompatibility } \\
\text { complex, class II, DO alpha }\end{array}$ \\
\hline ZNF642 & $-1,40$ & 0,025 & Zinc finger protein 642 \\
\hline GRK5 & $-1,39$ & 0,041 & $\begin{array}{l}\text { G protein-coupled receptor } \\
\text { kinase } 5\end{array}$ \\
\hline ZNF167 & $-1,38$ & 0,022 & Zinc finger protein 167 \\
\hline AARS & $-1,37$ & 0,021 & Alanyl-tRNA synthetase \\
\hline MARS & $-1,36$ & 0,041 & Methionyl-tRNA synthetase \\
\hline ZNF107 & $-1,35$ & 0,031 & Zinc finger protein 107 \\
\hline ZNF443 & $-1,35$ & 0,022 & Zinc finger protein 443 \\
\hline
\end{tabular}

Shown are 42 differentially expressed genes ( $p$-value $<0.05$ and cut-off 1.3 fold) that are downregulated in Th1Th17 vs. Th1 cells.

nuclear receptor Peroxisome Proliferator-Activated Receptor Gamma (PPARY), ATF5 (Activating Transcription Factor 5), KLF11 (Kruppel-like factor 11), PTEN (phosphate and tensin homolog), and ARTNL (Aryl Hydrocarbon Receptor Nuclear Translocator-Like, a tumor suppressor and negative regulator of the cell cycle [50])) (Figure 3E-F; Table 1; Additional file 2: Table S1). In contrast, Th1 cells preferentially express the mRNAs corresponding to the signal transducer SMAD2 (mediating signals related to TGF- $\beta$ [51]), the transcription factor GATA3 (associated to the Th2 polarization profile [52]), as well as 10 members of the zinc finger (ZNF) family, some of which bind DNA and repress transcription of multiple genes [53,54]: ZNF80, ZNF82, ZNF107, ZNF167, ZNF252, ZNF295, ZNF382, ZNF443, ZNF642, ZNF767 and ZNF827 (Figure 3F; Table 2; Additional file 3: Table S2). Consistent with previous findings by our group and others [30,31], the current microarray studies demonstrate that Th1 and Th1Th17 cells express similarly high levels of the Th1-specific transcription factor T-bet (data not shown). Thus, Th1Th17 and Th1 subsets express distinct transcription factors that control their differentiation, polarization and biological functions by regulating the transcription of distinct genes that may play a role in HIV permissiveness.

\section{Signal transduction}

The heat map of genes implicated in signal transduction shows the differential expression of different kinases that can influence the sensibility to various signals. TCR triggering in Th1Th17 vs. Th1 cells induced higher expression of mRNA corresponding to kinase MAPKAPK2/MK2 (mitogen-activated protein kinase-activated protein kinase 2, important for the sustained NF- $\mathrm{kB}$ activation [55]), RAPGEF3/Epac1 (an exchange protein activated by cAMP, its expression could promote cell adhesion [56]) and the homeodomain interacting protein kinase 2 (HIPK2, positive regulator of the tumor suppressor p53 [57]). In contrast, Th1 cells preferentially express the mRNA of the kinases 


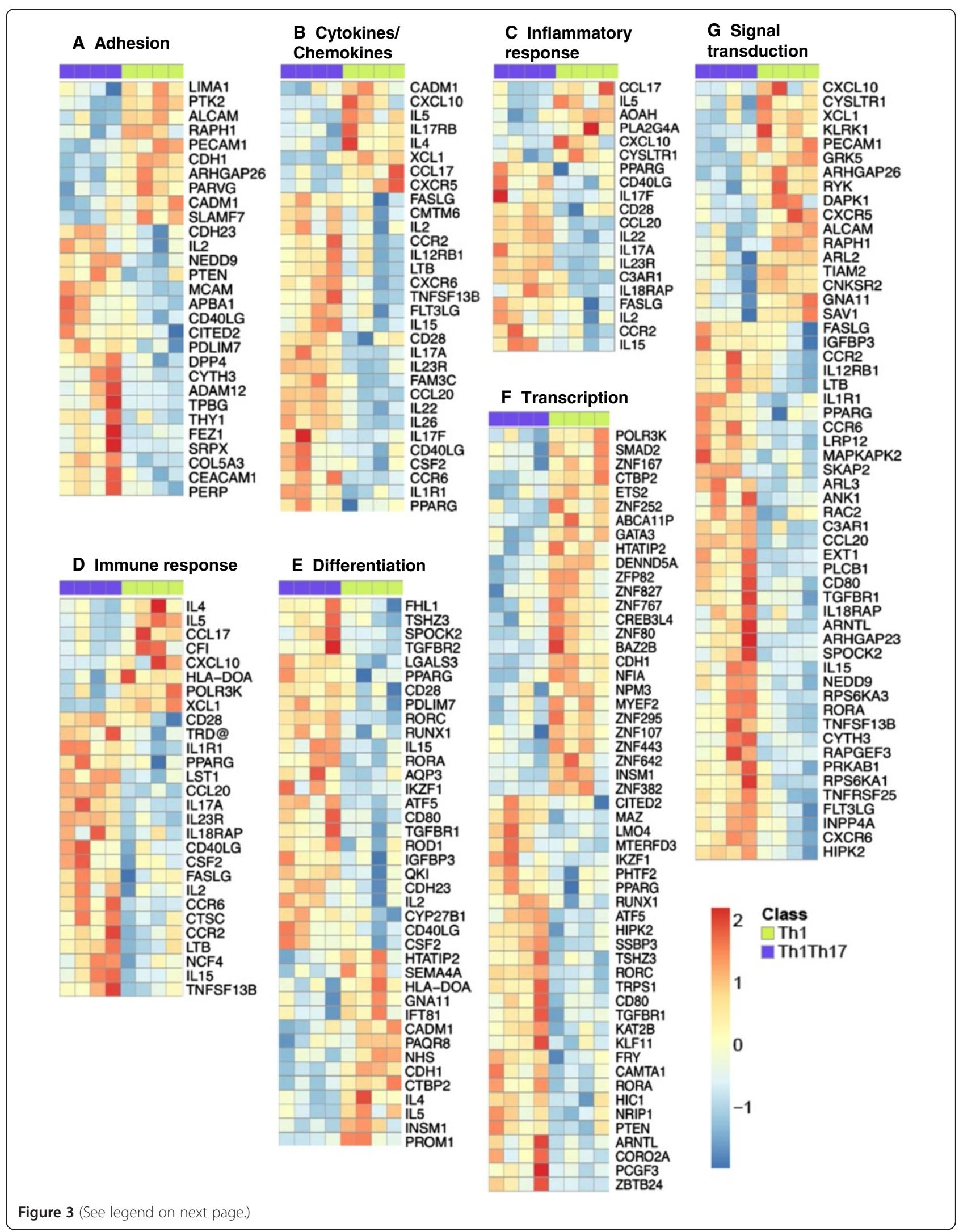


(See figure on previous page.)

Figure $3 \mathrm{GO}$ classification of differentially expressed genes in Th1Th17 vs. Th1 cells. Differentially expressed genes $(p<0.05, F C$ cut off 1.3$)$ in Th1Th17 vs. Th1 were classified based on their biological functions using GO as follows: Adhesion (A), Cytokines/Chemokines (B), Inflammatory responses (C), Immune responses (D), Differentiation (E), Transcription (F), and Signal transduction (G). The corresponding heat maps were generated using the R programming language and the pheatmap and ggplot2 libraries (R Core Team). For each heat map, genes expressed at higher and lower levels in Th1Th17 vs. Th1 are represented in red and blue, respectively. Results correspond to matched Th1Th17 and Th1 subsets described in Figure 2.

GRK5 (that inhibits the NF- $\mathrm{kB}$ transcriptional activity by inducing nuclear accumulation of IкB $\alpha[58,59])$, and CNKSR2/KSR2 (kinase suppressor of Ras 2, another negative regulator the NF-kB pathway [60]) (Figure 3I; Tables 1 and 2; Additional file 2: Table S1 and Additional file 3: Table S9). Of note, Th1Th17 express the killer cell lectin-like receptor subfamily B, member 1 (KLRB1/CD161) (Table 1), a known marker for Th17 precursors [61], while Th1 cells express the killer cell lectin-like receptor subfamily K, member 1 (KLRK1) (Figure 3G; Table 2). Thus, compared to Th1Th17 cells, Th1 polarized cells appear less favorable to activation and signal transduction of the NF-kB pathway, a signaling pathway implicated in HIV replication $[21,22]$.

RT-PCR validation of microarray results Among genes differentially expressed in matched Th1Th17 vs. Th1 cells (p-value $<0.05$ and FC cutoff 1.3) (Tables 1 and 2), a number of nine genes were selected by intelligent guess for validation at mRNA level. Among these transcripts, CXCR6 [62,63], PPAR [64-66], SERPINB6 [22], ARNTL [24], PTK2/FAK $[67,68]$ ), and ISG20 [43] were previously reported to play a role in regulating HIV replication, while PTPN13/FAP-1 [69-71] and MAP3K4/MEKK4 [72-74] are linked to T-cell activation. Quantitative real-time RT-PCR demonstrate that transcripts for CXCR6, PPAR $\gamma$, ARNTL, PTPN13, MAP3K4, and CTSH were significantly upregulated in Th1Th17 vs. Th1, while SERPINB6, PTK2, and ISG20 were downregulated (Figure 4). These results validated the differential expression of a set of transcripts in Th1Th17 vs. Th1 cells at mRNA level and suggest a potential role played by these molecules in the regulation of HIV permissiveness/resistance.

CEACAM1 and MCAM are new surface markers for Th1Th17 cells We further sought to validate the expression of two adhesion molecules at the protein level using flow cytometry: CEACAM1, a tumor marker [75] and broad inhibitor of T-cell function [76] and MCAM, a Th17 marker [77] and regulator of cell recruitment into the brain [78]. Results in Additional file 5: Figure S3 demonstrate a significantly higher expression of CEACAM1 and MCAM on Th1Th17 vs. Th1 cells ex vivo. Thus, CEACAM1 and MCAM are two new surface markers for Th1Th17 cells likely involved in regulating the in situ localization and function of these cells, with potential relevance for HIV pathogenesis.

The transcription repressor PPARY is preferentially expressed in Th1Th17 cells The nuclear receptor PPARy is a transcription factor known to inhibit Th17 differentiation in mice [79] and humans [80]. Here, we used fluorescence and confocal microscopy to validate differential expression of PPAR $\gamma$ protein in human Th1Th17 vs. Th1 cells at day 3 post CD3/CD28 triggering. Despite a marked heterogeneity in PPAR $\gamma$ expression within each subset, the expression of PPAR $\gamma$ protein was significantly higher in Th1Th17 vs. Th1 cells in two independent donors (Figure 5A-B). The analysis of cellular localization of PPAR $\gamma$ by confocal microscopy and z-stack reconstruction demonstrated the expression of PPARY in both nuclear and cytoplasmic compartments and a tendency for superior nuclear expression of PPAR $y$ in Th1Th17 vs. Th1 cells (Figure 5C). These results demonstrate an increased frequency of cells expressing PPAR $\gamma$ within human Th1Th17 vs. Th1 subsets and provide evidence that a partial PPAR $\gamma$ nuclear translocation occurs in Th1Th17 upon TCR triggering.

PPARy negatively regulates HIV replication in Th1Th17 cells The PPARy activation pathway restricts HIV replication in macrophages $[64,66]$. To investigate the role of PPAR $\gamma$ in regulating HIV permissiveness in Th1Th17 cells, we first used RNA interference to reduce levels of PPAR $\gamma$ mRNA prior HIV exposure. Given the difficulty of sorting sufficient numbers of Th1Th17 cells, siRNA experiments were performed on TCR-activated total memory $\mathrm{CD}^{+} \mathrm{T}$-cells from $\mathrm{n}=6$ different donors (Figure $6 \mathrm{~A}$ ). The efficacy of PPAR $\gamma$ mRNA and protein silencing was measured by RT-PCR and microscopy, respectively, at $24 \mathrm{~h}$, $48 \mathrm{~h}$, and $72 \mathrm{~h}$ post-nucleofection. In parallel, cells were exposed to the wild type (wt) NL4.3BaL R5 HIV strain or the single round HIV-VSVG-GFP strain at $24 \mathrm{~h}$ or $72 \mathrm{~h}$ post-nucleofection. Viral replication was monitored up to day 6 post-infection. Levels of PPARY mRNA were significantly decreased in $6 / 6$ donors at $24 \mathrm{~h}$ post-nucleofection (range silencing: 40-75\%) (Figure 6B). However, epifluorescence analysis (40X magnification) revealed a significant decrease in the PPAR $\gamma$ protein expression at $48 \mathrm{~h}(2 / 3$ subjects) and $72 \mathrm{~h}$ (3/3 subjects) but not at $24 \mathrm{~h}$ postnucleofection (Additional file 6: Figure S4A). The analysis 


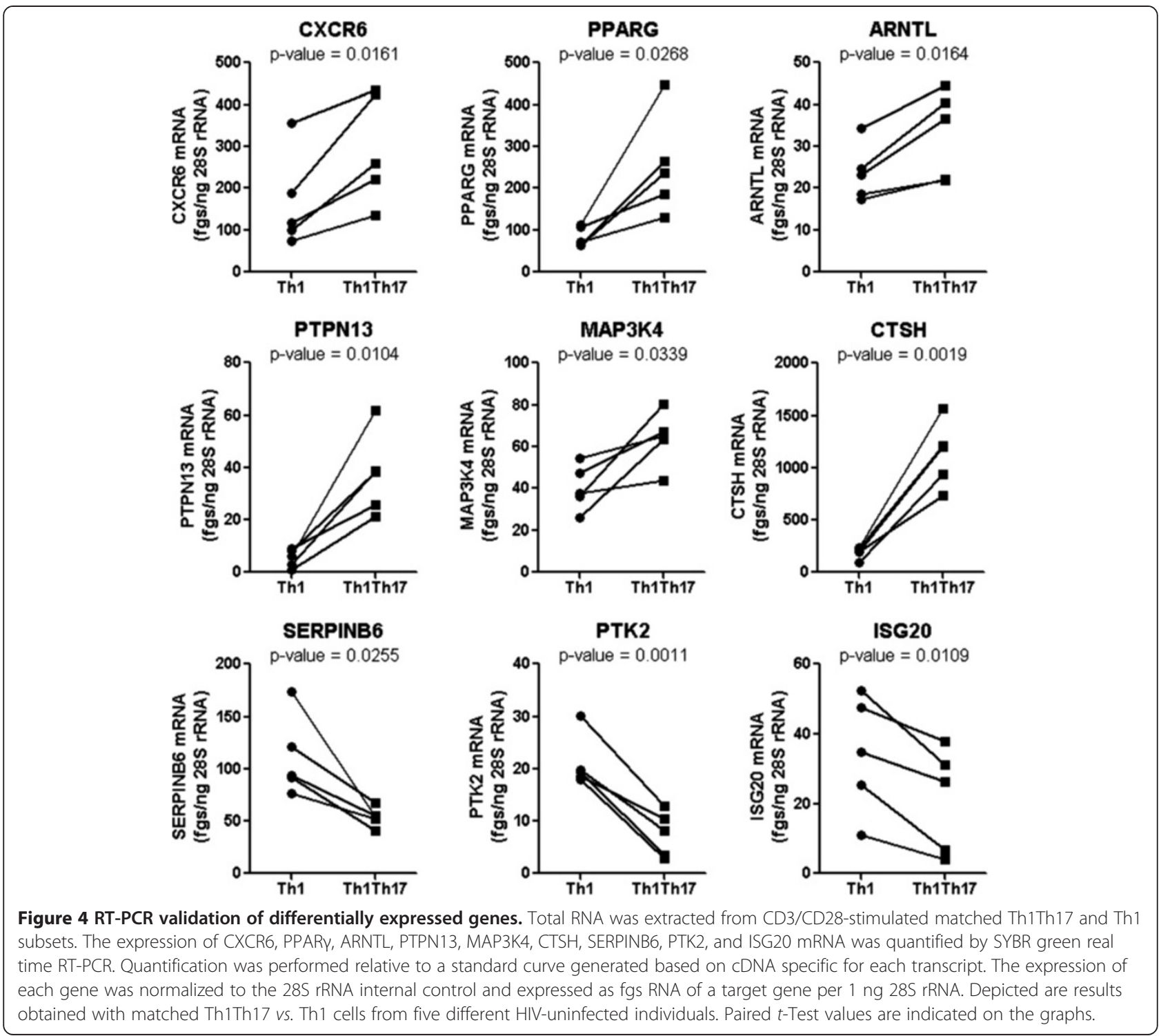

of cellular localization of PPAR $\gamma$ by confocal microscopy and $\mathrm{z}$-stack reconstruction demonstrated a significant depletion of the pool of PPAR $\gamma$ protein from both cytoplasm and nuclei at $72 \mathrm{~h}$ post-nucleofection (Additional file 6: Figure S4B). Cell viability (\% and counts of Vivid $^{-}$cells) and proliferation (\% Ki67 $7^{+}$cells) was not significantly different when nucleofection was performed using NT1 $v$ s. PPARY siRNA (Figure 6C-E), suggesting that subsequent differences in HIV permissiveness between NT1 and PPAR $\gamma$ siRNA are not linked to differences in cell toxicity caused by nucleofection. When cells were exposed to the replication competent NL4.3BaL 24 h post-nucleofection, PPAR $\gamma$ silencing was associated with a significant increase in HIV-DNA integration in 5/5 subjects at day 3 postinfection (Figure 6F; range increase: 150-200\%). In addition, PPAR $\gamma$ knock down resulted in enhanced viral replication as reflected by the HIV-p24 levels in supernatants at days 3 and 6 post-infection (Figure 6G) and the frequency of HIV-p24 ${ }^{+}$cells at day 7 post-infection (Figure $6 \mathrm{H}$ ). Thus, PPAR $\gamma$ restricts HIV replication in $\mathrm{CD}^{+}{ }^{+} \mathrm{T}$-cells.

To determine at which step in the viral life cycle PPARy interferes with HIV replication, similar experiments were performed with cells exposed to the single round HIVVSVG-GFP strain $24 \mathrm{~h}$ post-nucleofection with NT1 or PPAR $\gamma$ siRNA (Figure 7A). Results demonstrated that during one round of replication PPAR $\gamma$ knock down leads to a significant increase in HIV-DNA integration (Figure 7B) and transcription, as reflected by superior $\%$ and MFI GFP expression (Figure 7C). Despite a marked PPARy protein knock down at $72 \mathrm{~h}$ upon nucleofection, cell exposure to HIV at this time point reveal only minor differences in HIV replication between NT1 and PPARY siRNA (data 


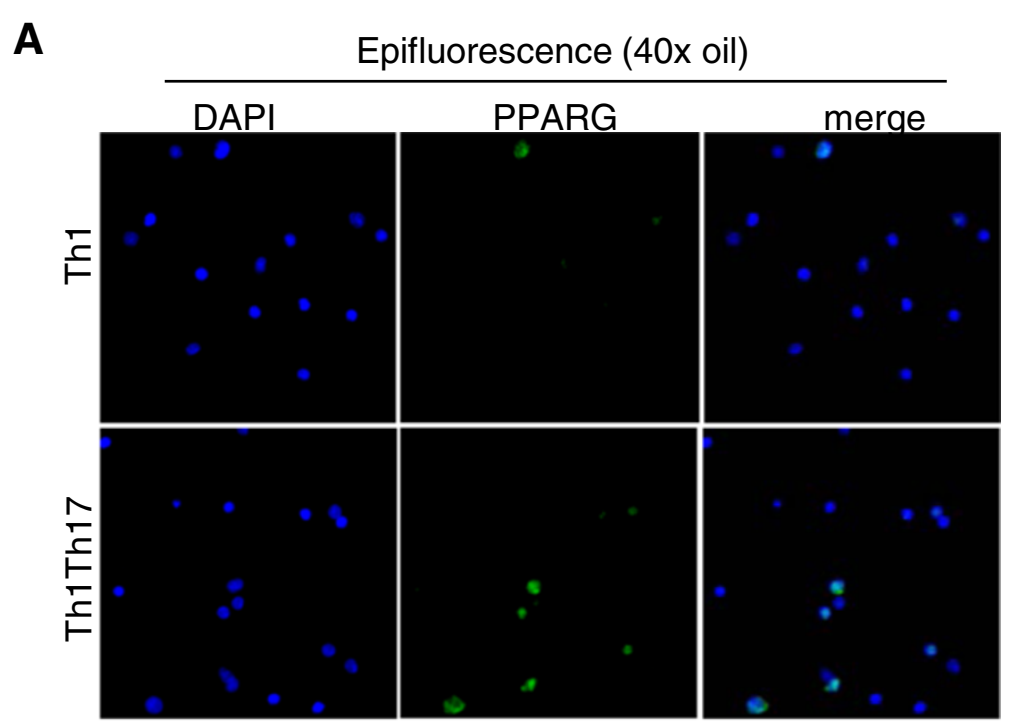

B

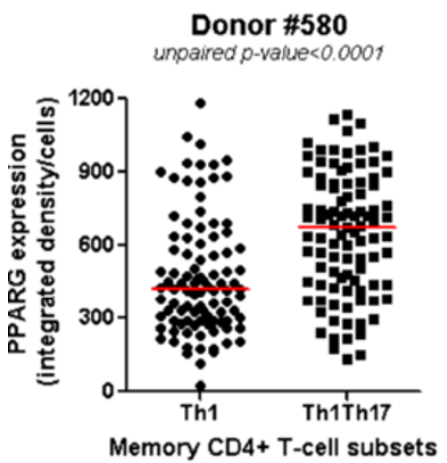

C

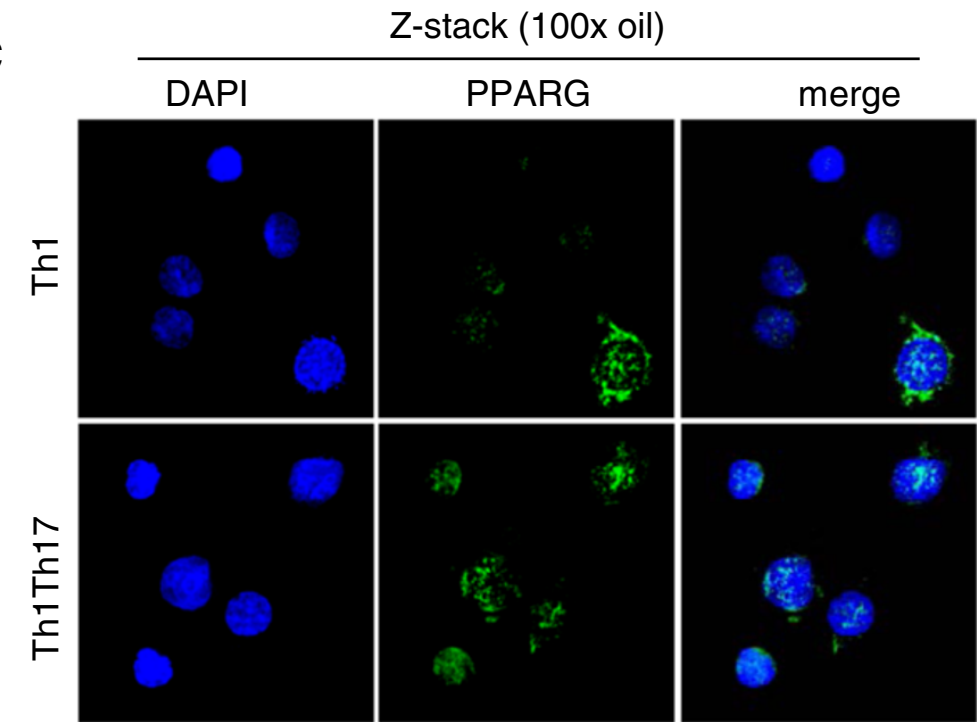


(See figure on previous page.)

Figure 5 Confocal microscopy quantification of PPARy expression in Th1Th17 vs. Th1 cells. Matched Th1Th17 and Th1 cells were stimulated via CD3/CD28 for 3 days. Cells were fixed on poly-L-lysine coated slides and intracellular staining was performed with rabbit anti-human PPARy Abs and then AlexaFluor 488 goat anti-rabbit Abs. Slides were mounted with the ProLong Gold Antifade reagent containing the nuclear dye DAPI. Slides were observed by fluorescence microscopy. (A-B) PPARy expression was observed by epifluorescence at 40x magnification. (A) Shown are fields of Th1 and Th1Th17 cells from one donor representative of two donors. (B) Shown is statistical analysis of PPARy expression in Th1 vs. Th1Th17 cells in two different donors ( $n=100$ cells per subsets per donor). Horizontal red lines indicate median values. Unpaired p-values are indicated on the figures. (C) The intracellular localization of PPARY was observed by maximum intensity z-projection of z-stack from representative field of each subset observed with a 100x oil objective in a spinning-disc confocal mode system. Shown images are representative of observations made with Th1 and Th1Th17 from two different donors.

not shown). This prompted us to investigate the kinetics of PPAR $\gamma$ mRNA expression upon nucleofection. Results in Additional file 7: Figure S5 reveal the recovery of PPAR $\gamma$ mRNA pool $72 \mathrm{~h}$ post-nucleofection. This may lead to the subsequent recovery of the PPAR $\gamma$ protein pool, thus explaining why differences in viral replication are not observed anymore when cell exposure to HIV is performed $72 \mathrm{~h}$ post-nucleofection. Altogether, these results identify PPARY as a negative regulator of HIV integration and replication in $\mathrm{CD}_{4}^{+} \mathrm{T}$-cells by acting at levels post-entry and prior HIV-DNA integration.

To further investigate the role of the PPAR $\gamma$ activation pathway in controlling HIV replication in T-cells, we used two PPAR $\gamma$ agonists: the synthetic rosiglitazone (RGZ) and the natural prostaglandin J2 (PGJ2). The PPAR $\gamma$-specific antagonist T007907 [81] was also used to counteract the effects of RGZ. Several doses of RGZ and PGJ2 were tested for their effects on cell viability and proliferation and on the expression of HIV receptor CD4 and coreceptor CCR5. RGZ at $1-100 \mu \mathrm{M}$ and PGJ2 at $1-10 \mu \mathrm{M}$ had no deleterious effects on cell viability and proliferation, and did not alter CD4 expression (Additional file 8: Figure S6A-D). RGZ did not alter CCR5 expression, while PGJ2 at 5 and 10 but not $1 \mu \mathrm{M}$ increased CCR5 expression (Additional file 8: Figure S6E), suggesting an unexpected facilitation of HIV entry via CCR5 by PGJ2. Doses of RGZ and PGJ2 that did not interfere with cell viability, proliferation, and CD4/ CCR5 expression were used in subsequent experiments. Confocal microscopy visualization of cells treated with RGZ $(50 \mu \mathrm{M})$, demonstrated a massive translocation of PPAR from the cytoplasm to the nucleus; this process was highly specific as it was efficiently reversed by simultaneous exposure to the antagonist T007907 (Additional file 9: Figure S7A-B). To determine the effect of PPAR $\gamma$ pathway activation on HIV replication, total memory $\mathrm{CD} 4^{+}$ T-cells were first exposed to HIV and then cultured in the presence or absence of RGZ (10, 50, $100 \mu \mathrm{M})$ and PGJ2 $(1 \mu \mathrm{M})$ (Figure 8A). Treatment with RGZ at 50 and 100 but not $10 \mu \mathrm{M}$ significantly reduced HIV replication at day 6 and 9 post-infection, while the PGJ2 at $1 \mu \mathrm{M}$ had no significant effect (Figure 8B-C). The quantification of HIV-DNA integration at early time points (day 3 postinfection) in cells treated with RGZ after HIV exposure did not reveal statistically significant differences (Figure 8D), suggesting that PPAR $\gamma$ pathway activation limits HIV replication by interfering with viral transcription. However, RGZ significantly decreased HIV-DNA integration at late time points (day 14 post-infection) (data not shown), suggesting that PPAR $\gamma$ pathway activation limits HIV dissemination upon long-term treatment. Finally, the role of PPAR $\gamma$ pathway in the negative regulation of HIV replication was tested in sorted Th1Th17 and Th1 cells from two independent donors. Results in Figure 8E-F illustrate that RGZ treatment dramatically reduced HIV replication in Th1Th17. RGZ also limited HIV replication in Th1 cells Figure $8 \mathrm{D}$, consistent with the fact that cells expressing PPAR $\gamma$ are also detected within the pool of Th1 cells (Figure 5). Together these results provide the first evidence that PPAR $\gamma$ acts as an intrinsic negative regulator of HIV replication in $\mathrm{CD} 4^{+} \mathrm{T}$-cells, including cells with a Th1Th17 polarization profile. PPAR $\gamma$ prevents new infection by acting at levels prior HIV-DNA integration. PPARy also acts on infected cells and limits replication and subsequent infection spreading to neighboring cells by acting at postintegration levels, likely during transcription.

\section{Discussion}

The goal of this study was to identify molecular mechanisms of HIV-1 regulation in Th1Th17 and Th1 cells, two cell subsets previously identified by our group as being highly permissive and relatively resistant to infection, respectively [31]. We performed a genome-wide analysis of gene expression in Th1Th17 and Th1 cells upon TCR signaling and prior HIV exposure. Our results demonstrate that (i) Th1Th17 cells have the potential to be recruited into sites of HIV persistence such as the intestine and the brain; (ii) pathways previously linked to HIV permissiveness, including the proximal TCR signaling and the NF$\kappa B$ activation pathway [21-26] are enriched in Th1Th17 vs. Th1 cells; and (iii) the transcriptional repressor PPAR $\gamma$ is an intrinsic negative regulator of HIV permissiveness in total $\mathrm{CD}^{+}{ }^{+} \mathrm{T}$-cells and mainly Th1Th17 cells by acting at post-entry levels, prior to HIV-DNA integration and/or transcription. Together, these results reveal that Th1Th17 cells exhibit a unique transcriptional program favorable to 


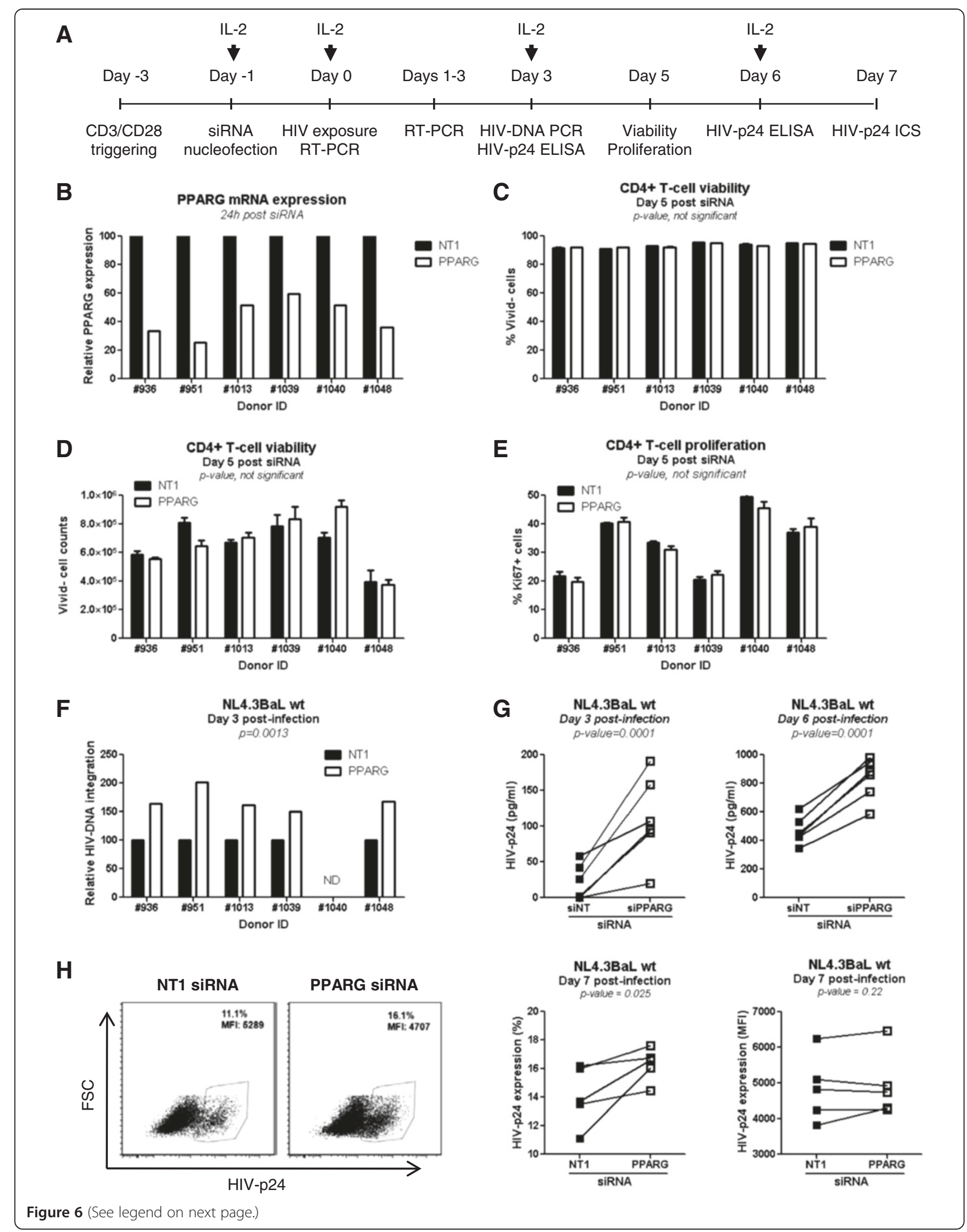


(See figure on previous page.)

Figure 6 PPAR 7 RNA interference increases HIV replication in memory $C D 4^{+}$T cells. Memory $C D 4^{+}{ }^{+}$-cells were isolated from thawed PBMC rested overnight by negative selection using magnetic beads. (A) Cells were stimulated via CD3/CD28 for 2 days, nucleofected with PPARy or non-targeting (NT1) siRNA, and then cultured for an additional $24 \mathrm{~h}$ at $2 \times 10^{6}$ cells/ml in the presence of IL-2. (B) RNA silencing efficiency was assessed by RT-PCR $24 \mathrm{~h}$ post-nucleofection $(n=6)$. (C-E) The effect of NT1 and PPARY siRNA on cell viability and proliferation was assessed by flow cytometry at day 6 post-nucleofection $(n=6)$. Cell viability was monitored using the viability dye Vivid $(\mathbf{C})$, cell counts were determined using FlowCounts fluorospheres (D), and cell proliferation was measured upon intracellular staining with Ki67 Abs (E). Cells were exposed to

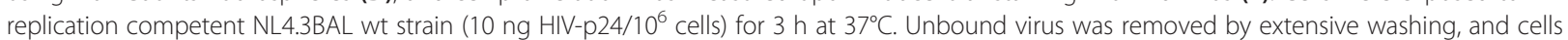
were maintained in culture in the presence of IL-2 up to 7 days post-infection. (F) Integrated HIV-DNA levels were quantified by real-time PCR in cells harvested at day 3 post-infection $(n=5)$. (G) Levels of HIV-p24 in cell supernatants were quantified by ELISA at days 3 and 6 post-infection $(n=6)$. $(H)$ At day 7 post-infection, cells were harvested and the frequency of infected cells was analyzed by flow cytometry upon intracellular staining with HIV-p24 Abs. Shown is the frequency of HIV-p24 cells (\% and MFI, mean fluorescence intensity) upon nucleofection with PPARy vs. NT1 siRNA in one representative subject (left panels) and statistical analysis in $n=5$ different subjects (right panels). Paired $t$-Test values are indicated on the graphs.

HIV replication that can be negatively regulated by the nuclear receptor PPAR $\gamma$.

Genome-wide transcriptional profiling demonstrated that, despite a high degree of transcriptional similarity, Th1Th17 and Th1 cells are distinguished by the differential expression of 780 probe sets (p-value $<0.05$ ), including 265 upregulated and 235 downregulated, respectively (FC cutoff 1.3). Transcripts differentially expressed in Th1Th17 vs. Th1 cells were classified using two systematic approaches: GSEA and GO. GSEA demonstrated that transcripts linked to p38 MAPK signaling, integrins, transendothelial migration, cytokine receptor interaction, IL-23 signaling, and circadian clock pathways were enriched in Th1Th17 cells. In contrast, transcripts linked to interferon type 1 signaling pathway, proteasome, and cell cycle were enriched in Th1 cells. Also, transcripts with promoters controlled by transcription factors such as RORA, Foxo1, Foxo4, AP-2, NF- $\mathrm{kB}$, and p53 were enriched in Th1Th17 vs. Th1 cells. GO classification by biological function revealed significant differences between Th1Th17 and Th1 cells relative to transcripts involved in cell adhesion, cytokines/ chemokines, inflammatory processes, immune responses, differentiation, transcription, and signal transduction. The finding that the NF- $\mathrm{BB}$ activation pathway, known for its implication in enhancing the transcription of different genes including the HIV LTRs [82], was enriched in Th1Th17 is consistent with results generated by siRNA screens for HIV-dependency factors in cell lines [21,24]. Several Th1Th17-specific transcripts were also recently identified by Imbeault et al. as being over expressed in HIV-infected $v s$. uninfected $\mathrm{CD}_{4}{ }^{+}$T-cells [42]. These transcripts are linked to $\mathrm{T}$-cell polarization (cytokines and transcription factors specific for Th17 and Th1 cells) and activation (CD80, CD40LG, NF- $\mathrm{B}$, Rho/Rac, RUNX1), susceptibility to apoptosis (FasLG, PTEN, p53), and regulation of viral replication (furin) [42]. Finally, our finding that gene sets linked to interferon type I signaling, including the antiviral factor ISG20 [43], are over expressed in Th1 cells is consistent with the up regulation of these pathways in HIV-resistant CMV-specific
$\mathrm{CD}^{+}$T-cells [36]. Thus, we provide evidence that HIV permissiveness in Th1Th17 vs. Th1 is associated with a superior state of cellular activation and limited antiviral properties.

Our study reveals that trafficking of Th1Th17 and Th1 cells is regulated by distinct adhesion molecules and chemokine receptors: CCR6, MCAM, CEACAM1, CCR2, and CXCR6 for Th1Th17 and PEACAM-1/CD31, ALCAM, and CXCR5 for Th1. CCR6 is a Th17 marker essential for their homing into Peyer's patches [83] and the central nervous system (CNS) [84]). MCAM facilitates entry into the CNS of T-cells involved in the pathogenesis of multiple sclerosis [78,85]. CCR2 is another Th17 marker [86] that also acts as minor co-receptor for HIV entry [87]). A polymorphism in CCL2 (a major CCR2 ligand) leading to increased chemokine expression was associated with AIDS dementia [88]. The CNS is a major HIV sanctuary established during the early phases of infection $[3,89]$. Recruitment of Th1Th17 cells into the brain via CCR6, MCAM, and CCR2 may significantly contribute to fueling HIV persistence. CEACAM1 expression is induced by activation [76] and plays a critical role in the regulation of $\mathrm{B}$ cell function at intestinal level [90]. The functional role of CEACAM1 ${ }^{+}$Th1Th17 cells in gut-associated lymphoid tissues (GALT), a major anatomic site for HIV replication [91], remains to be determined. CXCR6 is co-expressed with CCR5 on activated T-cells [63] and acts as a minor HIV coreceptor [92]. CXCR6 is also involved in the formation of the immunological synapse upon interaction with its ligand CXCL16, a membrane-bound chemokine expressed by DC $[62,93]$. This interaction my lead to efficient transmission of HIV within the virological synapse [94]. CXCL16 is also expressed by CD16 ${ }^{+}$monocytes [95]. The pro-inflammatory $\mathrm{CD} 16^{+}$monocytes are expanded in HIV-infected subjects [96], carry integrated HIV-DNA in vivo [97] and exhibit the ability to promote viral replication in $\mathrm{CD}^{+}{ }^{+} \mathrm{T}$ cells in vitro $[37,38]$. Thus, the interaction of Th1Th17 cells with DC or CD16 ${ }^{+}$monocytes via CXCR6-CXCL16 may contribute significantly to cell-tocell transmission of HIV in vivo. Consistent with this 


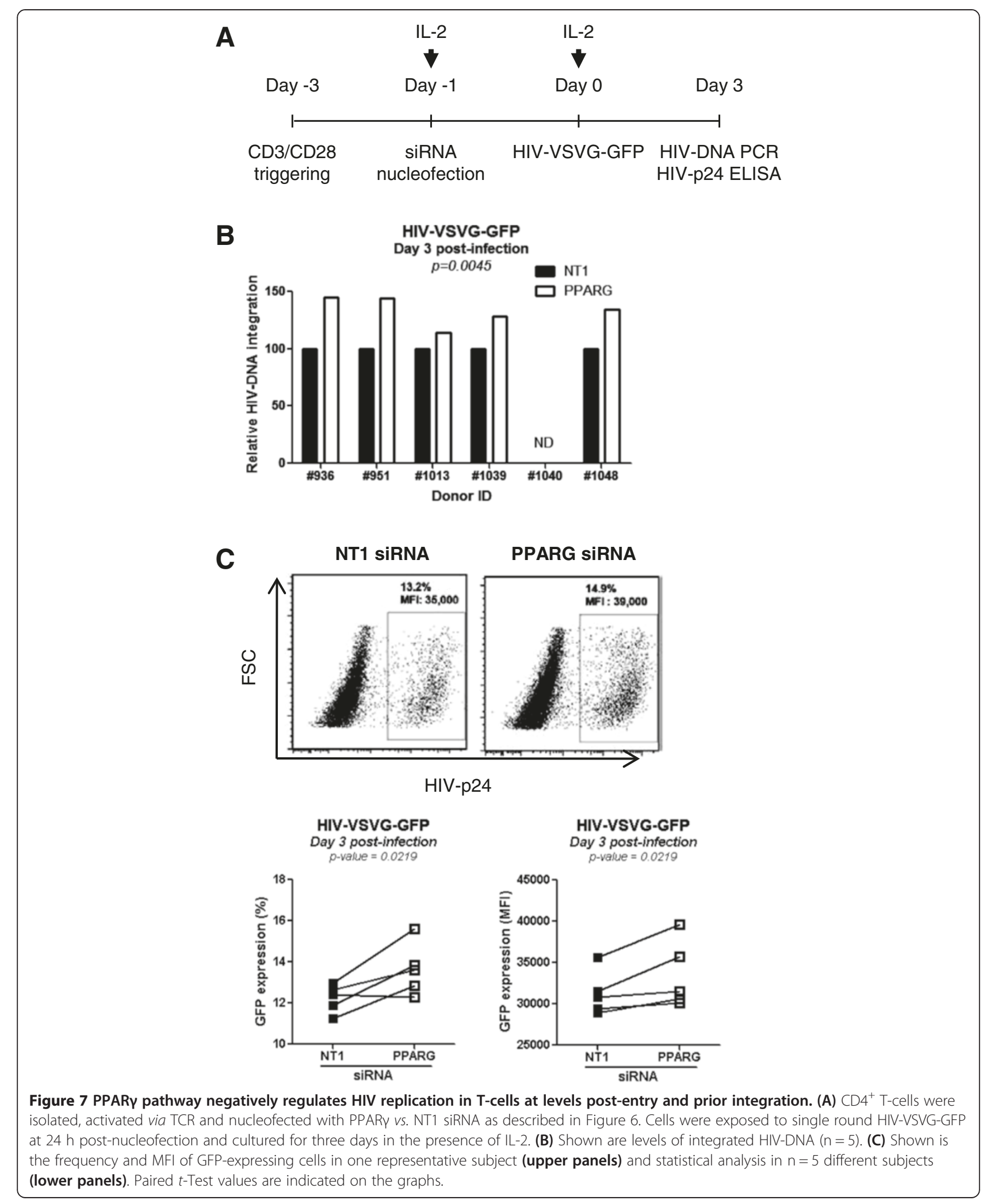

prediction, the CXCR6 polymorphism was associated with slow disease progression in HIV-infected people $[92,98]$. The fact that Th1Th17 cells express receptors regulating both HIV entry and migration into anatomic sites of viral replication place these cells in the first line of HIV targets and provides an explanation for their 


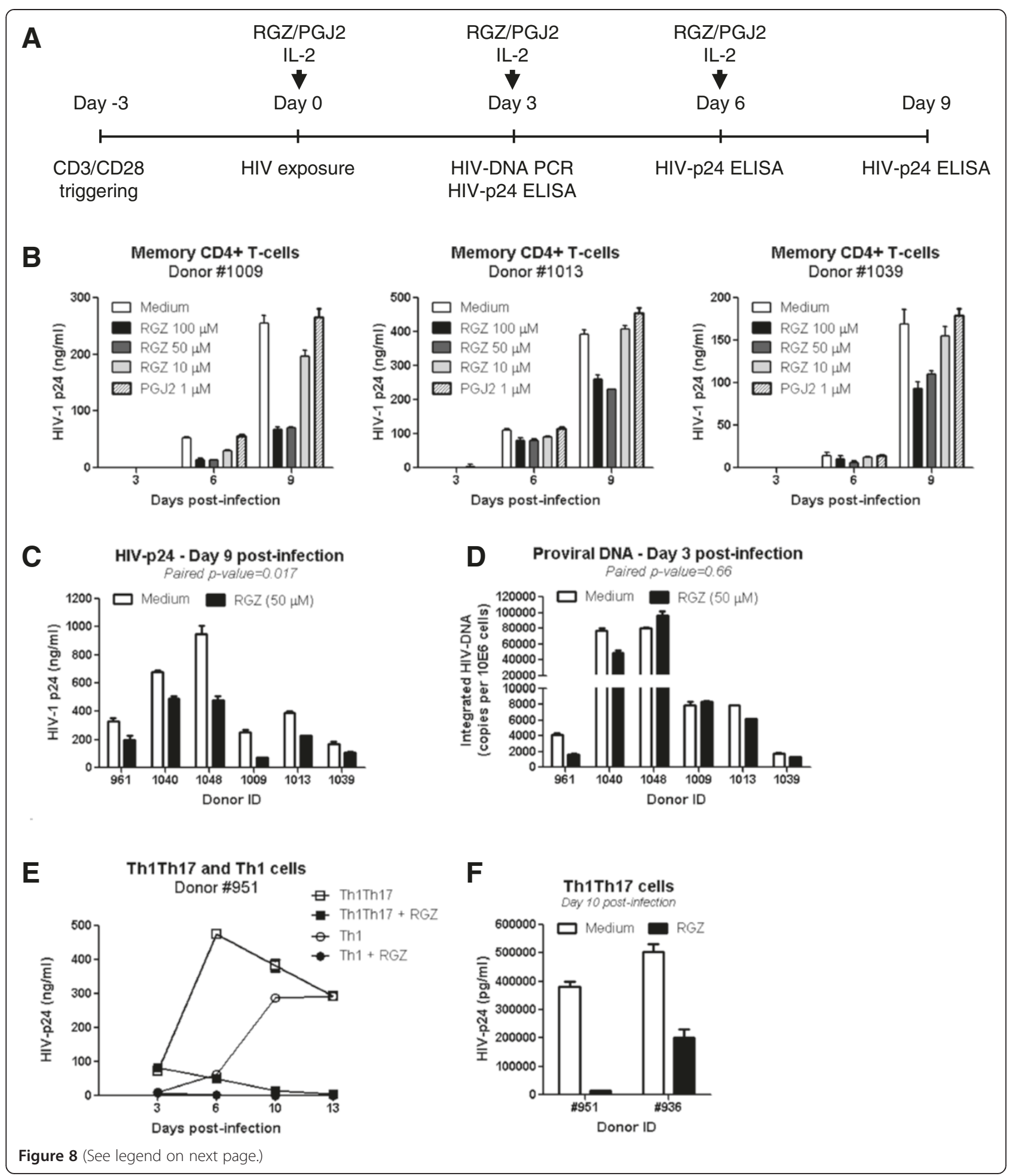


(See figure on previous page.)

Figure 8 Activation of PPARy pathway negatively regulates HIV replication in T-cells. Memory CD4+ T cells were stimulated via CD3/CD28 for 3 days. (A) Cells were then exposed to replication competent NL4.3BAL-GFP HIV (50 ng HIV-p24/106 cells) for $3 \mathrm{~h}$ at $37^{\circ} \mathrm{C}$. Unbound virus was removed by extensive washing. HIV-infected cells were cultured in the presence of IL-2 (5 ng/ml) and Rosiglitazone (RGZ; 10, 50, and 100 $\mu M)$ or prostaglandin J2 (PGJ2; $1 \mu \mathrm{M}$ ). Media was refreshed every 3 days. Supernatants were harvested at day 3, 6 and 10 post-infection for HIV-p24 quantification by ELISA, while a fraction of cells harvested at day 3 post-infection was used for integrated HIV-DNA quantification by real-time PCR. (B) Shown are kinetics of HIV-p24 expression in culture supernatants $(n=3$; mean \pm SD of triplicate wells). (C) Shown are statistics of HIV-p24 levels in supernatants collected at day 9 post-infection from memory CD4+ T-cells cultured in the presence or the absence of RGZ (50 $\mu M$ ) $(n=6)$. (D) Shown are integrated HIV-DNA levels at day 3 post-infection in memory CD4+ T-cells cultured in the presence or the absence of RGZ $(50 \mu \mathrm{M})$ upon infection $(n=6)$. (E) Matched Th1Th17 and Th1 cells were sorted by flow cytometry, stimulated and exposed to NL4.3BAL-GFP HIV as above, and cultured with IL-2 (5 ng/ml) in the presence or absence of RGZ $(50 \mu \mathrm{M})$. Levels of HIV-p24 were quantified by ELISA at days 3, 6, 10, and 13 post-infection. Shown are results from one donor representative of results obtained with cells from two different donors. (F) Shown are the effects of RGZ $(50 \mu \mathrm{M})$ on HIV replication in Th1Th17 cells from two different donors at day 10 post-infection. (C-D) Paired t-Test values are indicated on the graphs $(n=6)$.

depletion in HIV-infected subjects, including subjects under viral-suppressive ART [31].

The autocrine production of CCR5-binding chemokines protects $\mathrm{CD}^{+}{ }^{+} \mathrm{T}$-cells from HIV infection $[32,33]$. Our microarray studies did not reveal differences between Th1Th17 and Th1 cells in the expression of these transcripts, consistent with our previous results [31]. However, the upregulation in Th1 vs. Th1Th17 cells of the PTK2/ FAK, a kinase whose activation is linked to CCR5 triggering $[67,68]$, suggests that CCR5-binding chemokines act on Th1 cells and may limit this way HIV entry. This scenario is consistent with the finding that differences in HIV-DNA integration were marginally significant when cells where exposed to a single round VSV-G-pseudotyped HIV. Nevertheless, levels of GFP expression, indicative of HIV transcription, were higher in Th1Th17 vs. Th1 cells suggesting that regulatory mechanisms at both entry and post-entry levels control HIV permissiveness in Th1Th17 vs. Th1 cells.

Of particular interest, Th1 cells expressed transcripts corresponding to KLRK1/NKG2D, an activating receptor typically expressed on cytotoxic NK cells and $\mathrm{CD} 8^{+} \mathrm{T}$-cells [99]. The acquisition of cytotoxic antiviral function was previously reported for CMV-specific cells [100], which exhibit indeed a Th1 polarization profile [30] and are protected from infection $[32,33,36]$. The acquisition of cytotoxic antiviral functions may contribute to the intrinsic HIV resistance in Th1 cells thus, explaining the expansion of Th1 cells in HIV-infected subjects [31]. An increased frequency of Th1 cells in HIV-infected subjects may be deleterious given the ability of these cells to produce pro-inflammatory cytokines such as TNF [31]. In addition, the finding that Th1 vs. Th1Th17 cells over expressed the CDH1 mRNA (E-cadherin), known to inhibit HIV-specific $\mathrm{CD} 8^{+} \mathrm{T}$-cell functions via interaction with its receptor KLRG1 [101], suggests a deleterious role of Th1 cells in HIV pathogenesis.

In addition to known Th17-specific transcription factors (RORC, RORA $[48,49]$ ), we demonstrate that Th1Th17 vs. Th1 expressed at superior levels the transcription factors
RUNX1, known to mediate the transactivation of RORC [102]; ATF5, involved in T cell activation [103]; ARTNL, a component of the circadian clock [104] and an HIV dependency factor [24]; PPAR $\gamma$ [105-107]; and also KLF11, which is a PPAR $\gamma$ co-regulator and direct transcriptional target [108]. HIV permissiveness in Th1Th17 cells was also associated with superior expression of the costimulatory molecules CD28 and CD40LG/CD154, molecules involved in the regulation of apoptosis such as FASLG, and cytokines such as IL-2 and IL-15. The expression of TGFBR1/ TGFBR2 and IL23R on Th1Th17 cells is indicative of their ability to respond to TGF- $\beta$ and IL-23, respectively. TGF- $\beta$ is essential to Th17 differentiation $[47,109]$, while IL-23 is involved in the maintenance of the Th17 polarization [46] and critical for the development of a pathogenic Th17 profile [47].

The expression of genes important for signal transduction downstream of the TCR and/or cytokine receptors also indicates a greater susceptibility of Th1Th17 cells to activation and a potential contribution to inflammation. For example, Th1Th17 cells preferentially express MAPKAPK2/MK2, a kinase involved in the production of TNF$\alpha$ and IL-6 [110] and MAP3K4, a kinase involved the p38/ JNK pathway activation in response to TGF- $\beta$ [74]. Indeed, signaling through p38 is important for HIV replication [111]. In contrast to Th1Th17, Th1 cells expressed at superior levels several 10 genes of the zinc finger (ZNF) family, including the ZNF382, a tumor suppressor acting via the inhibition of the NF-kB signaling pathway [112]. Also, Th1 cells preferentially express GRK5 and CNKSR2/ KSR2, two molecules that can inhibit the transcriptional activity of NF- $\mathrm{kB}[58,60]$. Interestingly, genome-wide siRNA screens for HIV dependency factor (HDF) identified NF- $\mathrm{BB}$ pathway as being key for HIV permissiveness [21,22,24]. It was also shown that the HIV LTR promoters have binding sites for NF- $\mathrm{kB}$ that are important for the transcription of the virus [82]. It would be of interest to determine whether the expression of kinases GRK5 and CNKSR2 limits NF- $\mathrm{kB}$ translocation in Th1 cells thus, explaining their resistance to HIV infection. 
One major finding of our study is the identification of PPAR $\gamma$ as an intrinsic negative regulator of HIV permissiveness in Th1Th17 cells. PPAR $\gamma$ is a ligand-dependent nuclear receptor that acts as a transcriptional repressor in macrophages [105] and T-cells [106,107]. The localization of PPAR $\gamma$ in the nucleus vs. the cytoplasm is influenced by the interactions with its endogenous ligands [107]. Confocal microscopy analysis revealed not only an increased frequency of PPAR $\gamma$ expressing cells, but also superior nuclear vs. cytoplasmic localization of PPAR $\gamma$ protein in Th1Th17 vs. Th1 cells, suggesting the existence of endogenous ligands triggering PPAR $\gamma$ nuclear translocation in Th1Th17 cells upon TCR engagement. Whether PPAR $\gamma^{+}$ vs. PPAR ${ }^{-}$cells within the Th1Th17 and also the Th1 pool are particularly permissive to infection and whether the nuclear localization of PPARy contribute to limiting HIV permissiveness in such cells remains unknown. Future studies are needed to determine the role of PPAR $\gamma$ endogenous ligands in controlling HIV permissiveness in primary cells.

Our results demonstrate that PPAR $\gamma$ activation pathway controls HIV dissemination by acting on HIV-infected cells and also by preventing new integrative infection. We found that siRNA against PPAR $\gamma$ led to a significant increase in HIV-DNA integration and subsequent viral replication when cells were exposed to wt HIV 24 h after PPAR $\gamma$ knock down. Of note, similar results were obtained when cells were exposed to single round VSV-G pseudotyped virions that enter cells independently of CD4 and coreceptors. Thus, we provide evidence that PPAR $\gamma$ exerts its inhibitory effects post-entry and prior HIV-DNA integration. The activation of the PPARY pathway using the synthetic agonist RGZ upon HIV exposure demonstrated a strong inhibition of HIV replication. Consistent with previous studies on dendritic cells (DC) [113], RGZ did not affect the expression of CD4 and CCR5 thus providing further evidence that PPAR $\gamma$ activation interferes with HIV replication at post-entry levels. Treatment with RGZ induced a complete nuclear translocation of PPAR $\gamma$, and this phenomenon was reversed by simultaneous exposure to the antagonist T007907. The effects of RGZ on HIVDNA integration was observed at late but not early time points post-treatment thus, suggesting that nuclear translocation of PPAR $\gamma$ in HIV-infected cells limits viral replication by regulating directly or indirectly HIV transcription and subsequent HIV dissemination. Unexpectedly, the natural PPAR $\gamma$ agonist PGJ2 exerted no effect on HIV replication, in contrast to previous studies on different cell types [66,114], suggesting that PGJ2 effects are cell-dependent. One potential explanation is related to the fact that PGJ2 exerts PPAR $\gamma$-independent effects [115]. Another explanation may be that Th1Th17 selectively express transcripts for hydroxyprostaglandin dehydrogenase 15-(NAD) (HPGD) (Table 1), an enzyme involved in PGs degradation [116]. Whether, HPGD degrades exogenous PGJ2 remains unknown. Finally, we observed that RGZ dramatically decreased HIV replication in sorted Th1Th17 cells thus demonstrating that PPAR $\gamma$ indeed negatively controls the HIV permissiveness program in these cells. The ability of RGZ to control HIV replication in Th1Th17 cells but also in total CD4 ${ }^{+} \mathrm{T}$-cells is of interest in view of future therapies targeting PPAR $\gamma$ nuclear translocation in vivo.

Other studies demonstrated the ability of PPAR $\gamma$ agonists to inhibit HIV replication in vitro $[66,113,114]$ or in animal models of HIV encephalitis by acting on macrophages [64]. Also, PPARy signaling inhibits DC-mediated HIV capture and trans-infection at least in part by depleting cholesterol from the cell membrane [113]. Of note, two negative regulators of the PPAR $\gamma$ signaling, NCOR and COUP, were previously identified as HDFs in siRNA screenings performed in HeLa [21] and Jurkat cells [24], respectively. Our results provide the first evidence that HIV-permissive Th1Th17 cells highly express PPAR $\gamma$, which acts as an intrinsic negative regulator of viral replication. These effects may be explained by different indirect mechanisms including the anti-inflammatory properties of PPAR $\gamma$ $[107,117]$, the alteration of the cholesterol metabolism $[113,118]$, and/or by the ability of PPAR $\gamma$ to repress RORC expression and subsequently inhibit Th17 differentiation $[79,80]$. In addition to these indirect effects, there is evidence supporting a directed capacity of PPAR $\gamma$ to repress HIV LTR activity $[64,119]$. A very recent sequence analysis of the HIV-1 5' -LTR region in viral isolates from different geographic regions, suggests the possible conservation of PPAR binding sites [120]. Thus, PPAR $\gamma$ represent a robust negative regulator of $\mathrm{HIV}$ replication in permissive $\mathrm{CD}_{4}^{+}$ T-cells, such as Th1Th17 cells, via both direct and indirect mechanisms of HIV integration and transcription regulation.

\section{Conclusions}

To our knowledge, this is the first genome-wide characterization of differential gene expression in primary Th1Th17 vs. Th1 cells that we previously identified as being relatively permissive and resistant to HIV infection, respectively [31]. This study identifies new markers regulating Th1Th17 trafficking and functions (MCAM, CEACAM1, CXCR6), the NF- $\mathrm{kB}$ as a major pathway involved in the positive control of HIV permissiveness, and the PPAR $\gamma$ pathway as a negative regulator of HIV replication in primary $\mathrm{CD}_{4}^{+}$T-cells. PPAR $\gamma$ agonists, initially discovered as anti-diabetic drugs [121], are of therapeutic interest in humans given their anti-inflammatory properties. In HIV-infected subjects, PPAR $\gamma$ agonists are already used to treat chronic metabolic abnormalities [122]. Given our current findings on the PPAR $\gamma$-mediated negative control of $\mathrm{HIV}$ replication in $\mathrm{CD}^{+} \mathrm{T}$-cells, together with studies 
by other groups demonstrating similar effects on macrophages [64,66] and DC [113], a new generation of non-toxic PPARY agonists may help reduce covert viral replication in HIV-infected subjects receiving ART. This additional therapeutic strategy may decrease the pool of HIV-permissive cells and thus subsequently reducing viral reservoirs especially when administered during the early phases of HIV infection.

\section{Methods}

\section{Subjects}

HIV-uninfected donors were recruited at the Montreal Chest Institute, McGill University Health Centre and Saint-Luc Hospital, Montréal, QC, Canada, through the FRSQ/SIDA-MI Network (Québec, Canada). Informed consent and Internal Review Board approval were obtained for all participants. Peripheral blood mononuclear cells (PBMC) $\left(10^{9}-10^{10}\right.$ cells) were collected by leukapheresis as previously reported [123] and used frozen.

\section{Antibodies and polychromatic flow cytometry analysis} Fluorochrome-conjugated Abs used for polychromatic flow cytometry analysis were CD3-Pacific Blue (UCHT1), CD4Alexa Fluor 700 (RPA-T4), CD45RA-APC-Cy7 (H1100), CCR4-PE-Cy7 (1G1), CXCR3-PE-Cy5 (1C6), CCR6-PE (11A9), CCR5-PE (2D7) and CEACAM1-FITC (B1.1) (BD Pharmingen), CD56-FITC (MEM188) (eBioscience), CD8FITC (BW135/80), CD19-FITC (LT19), and MCAM-FITC (541-10B2) (Miltenyi Biotec). The viability dye Aqua Vivid (Invitrogen) was used to exclude dead cells from our analysis. Cells were analyzed by FACS using the BD LSRII cytometer, and BD Diva and FlowJo softwares (Tree Star, Inc). Positivity gates were placed using fluorescence minus one (FMO), as previously described [124].

\section{Magnetic (MACS) and fluorescence activated cell sorting (FACS)}

Memory Th1Th17 and Th1 were sorted as previously described [31,125]. Briefly, total CD4 ${ }^{+}$T-cells were sorted from PBMCs by negative selection using magnetic beads (Miltenyi), memory (CD45RA-) Th1Th17 (CXCR3 ${ }^{+}$CCR4$\mathrm{CCR}^{+}$phenotype) and Th1 (CXCR3 ${ }^{+} \mathrm{CCR}^{-}{ }^{-} \mathrm{CCR} 6^{-}$phenotype) subsets were sorted by FACS (BD Aria II cytometer) upon staining with anti-CD45RA-APC-Cy7, CCR4-PE-Cy7, CXCR3-PE-Cy5, CCR6-PE and a cocktail of FITC conjugated Abs to exclude CD8 ${ }^{+} \mathrm{T}$-cells (CD8), NK cells (CD56), and $\mathrm{B}$ cells $(\mathrm{CD} 19)$. The sorting gate was set on CD45RA FITC $^{-} \mathrm{CCR}^{-} \mathrm{CXCR}^{+}{ }^{+}$cells expressing or not CCR6. The purity of the cells was typically $>98 \%$ for memory $\mathrm{CD}^{+}$ T-cells (CD45RA $\left.{ }^{-}\right)$and $>95 \%$ for Th1Th17 and Th1 subsets (Additional file 1: Figure S1). The median frequency of memory Th1 and Th1Th17 cells within total CD4 ${ }^{+}$ T-cells is $17.6 \%$ and $6.5 \%$, respectively $(\mathrm{n}=21)$ (data not shown). Typically, $4 \times 10^{6}$ Th1Th17 cells can be isolated by MACS and FACS from approximately $10^{8}$ total CD4 $4^{+}$ T-cells and $10^{9}$ PBMC (sorting yield $>50 \%$ ). For other experiments, memory $\mathrm{CD} 4^{+} \mathrm{T}$-cells were sorted by negative selection using magnetic beads at a purity $>98 \%$ as demonstrated by staining with CD3, CD4, and CD45RA Abs (data not shown).

\section{RNA isolation and microarray analysis}

Sorted Th1Th17 and Th1 subsets were stimulated with immobilized CD3 and soluble CD28 Abs $(1 \mu \mathrm{g} / \mathrm{ml})$ for 3 days. Total RNA was isolated using the RNeasy kit (Qiagen) according to the manufacturer's protocol and quantified by Pearl nanophotometer (Implen, Munich, Germany) (typically, $10^{6}$ cells yielded 3-5 $\mu \mathrm{g}$ RNA). Genome-wide analysis of gene expression was performed on total RNA extracted from Th1Th17 and Th1 cells of four different HIV-uninfected donors by Génome Québec (Montreal, Qc, Canada) using the Affymetrix technology. Briefly, the quality of total RNA was first tested using an Agilent 2100 Bioanalyzer chip. Then, high quality RNA was reverse transcribed and hybridized on the GeneChip ${ }^{\circ}$ Human Genome U133 Plus 2.0 Array (Affymetrix). This chip includes 54,675 probe sets on a single array (i.e., 47,000 transcripts and variants, including 38,500 wellcharacterized human genes). Gene expression data was analyzed using Bioconductor [126], an open-source software Library for the analyses of genomic data based on R, a programming language and environment for statistical computing and graphics (www.r-project.org). The R software package was used to preprocess and normalize the probes intensities using RMA [127] method for the four matched Th1Th17 and Th1 cell subsets.

\section{Microarray data analysis}

Genes were filtered by detection call and by variance filters to allow a reduction in the number of tests and a corresponding increase in power of the differential gene expression analysis [128]. The resulting matrix showing 38,113 probes as present calls was $\log _{2}$ transformed and used as input for linear modeling using Bioconductor's limma package (Linear Models for Microarray Data), which estimates the fold-change (FC) between predefined groups (Th1Th17 vs. Th1 cell subsets) by fitting a linear model and using an empirical Bayes method to moderate standard errors of the estimated log-fold changes for expression values from each gene. P-values from the resulting comparison were adjusted for multiple testing according to the method of Benjamini and Hochberg. This method controls the false discovery rate (FDR), which was set to 0.05 . Determination of regulated gene expression is based on the nominal p-values. The entire microarray dataset and technical information requested by Minimum Information About a Microarray Experiment (MIAME) are available at the Gene Expression Omnibus (GEO) database 
under accession number GSE50175. Differentially expressed genes (cut-off 1.3-fold; $\mathrm{p}<0.05$ ) were classified through Gene Ontology using the NetAffx web-based application (Affymetrix). Corresponding heat maps for biological function categories were generated using programming language R.

\section{Gene set enrichment analysis}

Gene set enrichment analysis (GSEA) and Molecular Signature DataBase (MSigDB, Broad Institute, MIT, Cambridge, MA) were used to identify differentially expressed gene sets [41]. Microarray results were analyzed through collections C2, C3, and C5 of MsigDB latest version (4.0), yielding enrichment scores (ES) for each gene sets representing the difference between the observed and expected rankings from phenotype correlation. Merged to $\mathrm{C} 2$ are 28 gene sets collected from transcriptional analyses of the blood in immunological context named M x.x (eg. M 1.3) (their descriptions are not available through MsigDB, but can be found in Chaussabel et al. [129]), 24 immunological or signaling pathways from NetPath [130], and 132 gene sets from the Munich Information Center for Protein Sequences (CORUM MIPS; [131]). ES was then estimated by using a pre-ranked genes procedure based on the tstatistics of every transcript used in the linear model for gene expression. Nominal p-values were adjusted for multiple testing using the Benjamini and Hochberg method to control the FDR. Normalized enrichment scores (NES) were calculated for each gene set to account for the size of the set.

\section{Quantitative SYBR Green real- time RT-PCR}

Total RNA was isolated using RNeasy kit (Qiagen) from Th1Th17 and Th1 subsets of HIV-uninfected individuals. The quality (260/280 ratio) and quantity of RNA collected were measured by a Pearl nanophotometer (Implen, Munich, Germany). One step SYBR Green real-time RT-PCR (Qiagen) was carried out in a LightCycler 480 II (Roche) according to manufacturer's recommendations. CXCR6, PPARY, SERPINB6, PTK2, PTPN13, MAP3K4, ARNTL, and CTSH primers were purchased from Qiagen (QuantiTect Primer Assay). Quantifications were performed as previously described [95]. Briefly, $5 \mathrm{ng}$ total RNA was reverse transcribed in $20 \mu \mathrm{l}$ SYBR Green mix (Qiagen) containing $0.5 \mu \mathrm{M}$ primers. Agarose gel electrophoresis was used to visualize the size of the amplification products and to perform cDNA purification using the QIAquick Gel Extraction Kit (Qiagen) for standard curve preparation. Serial dilution of purified RT-PCR products $(20,000$; 2,000; 200; 20; 2; 0.2 fg cDNA) was used for the absolute quantification of target gene expression. The expression of each gene was normalized relative to the internal control $28 \mathrm{~S}$ rRNA levels (forward 5'-CGAGATTCCTGTCCCC ACTA-3'; reverse 5' -GGGGCCACCTCCTTATTCTA-3',
IDT, [95]). Melting curve analysis performed after realtime amplification revealed the uniformity of thermal dissociation profile per amplification product. Samples without template or without reverse transcriptase were used as negative controls. Each RT-PCR reaction was performed in triplicata.

\section{Fluorescent microscopy and quantitative image analysis}

Sorted Th1Th17 and Th1 cells were stimulated via CD3/ CD28 for 3 days $(1 \mu \mathrm{g} / \mathrm{ml})$. Cells were harvested and placed into poly-L-lysine-coated 8-wells glass culture slides (BD Biosciences) $\left(10^{5}\right.$ cells/well), spun down for $1 \mathrm{~min}$ at $1500 \mathrm{rpm}$, and fixed with $4 \%$ formaldehyde for $30 \mathrm{~min}$ at room temperature. Cells were permeabilized $5 \mathrm{~min}$ at room temperature in PBS, 1\% BSA, $0.5 \%$ Triton X-100. Cells were stained with rabbit anti-human PPAR $\gamma$ Abs (C26H12, Cell Signaling) overnight at $4^{\circ} \mathrm{C}$ and then with Alexa Fluor 488-conjugated goat anti-rabbit Abs (Invitrogen) for $2 \mathrm{~h}$ at room temperature. Slides were mounted using ProLong Gold Antifade medium with the nuclear dye DAPI (Invitrogen, Molecular Probes). Epi-fluorescent and Spinning Disc confocal microscopy images were carried out on an automated Cell Observer $\mathrm{Z1}^{\circ}$ microscope (Carl Zeiss) using the AxioVision 4.8.2 software (Carl Zeiss), except otherwise mentioned in the figures. For statistical analysis of protein expression in Th1Th17 and Th1 cells, random epi-fluorescent images were acquired with the 40x oil immersion objective (numerical aperture, NA, 1.3). All acquisitions between the different T-cell subsets were performed with the same illumination status in the same run. Integrated density was measured after background subtraction with Image J software (NIH). Data were compared by analysis of integrated density/area for 50-100 cells/subset. For the analysis of PPAR $\gamma$ cellular localization in different subsets, spinning disc confocal images were acquired using the 100x oil immersion objective (NA, 1.46) and maximum intensity projection of $0.2 \mu \mathrm{m}$ $\mathrm{z}$-stack sections were realized using ImageJ software after background subtraction. The ratio between nuclear and total PPAR $\gamma$ expression (integrated density units) was calculated on 10-16 sections/cell and mean \pm SD were calculated on five different cells representative/subset.

\section{HIV infection and quantification of viral replication}

The following HIV-1 molecular clones were used in this study: (i) the replication competent wild type CCR5-using (R5) NL4.3 strain with the BAL envelope (NL4.3BAL wt); (ii) the NL4.3BAL expressing $g f p$ in place of $n e f$ (NL4.3BAL-GFP); and (iii) single round env-deficient NL4.3 provirus expressing $g f p$ in place of nef pseudotyped with the VSV-G envelope (HIV-VSVG-GFP) that enter cells independently of HIV receptor and coreceptors, as previously reported [38]. The HIV stocks were produced and titrated as previously described [31] and used to infect 
cells (10 or 50 ng HIV-p24 per $10^{6}$ cells). Unbound HIV was removed by extensive washing, and cells were cultured at a concentration of $10^{6}$ cells per milliliter in RPMI1640, 10\% FBS, and IL-2 (5 ng/ml; R\&D Systems). Cell culture supernatants were harvested every 3-4 days and viral replication was measured by HIV-p24 ELISA. In parallel, cells were harvested at day 3 post-infection and cell lysates were used for real-time PCR quantification of integrated HIV-DNA ( $10^{5}$ cells per test in triplicata), as previously described $[6,31]$.

\section{PPARY RNA interference}

PBMC were thawed and rested overnight at $37^{\circ} \mathrm{C}$. Memory $\mathrm{CD} 4^{+} \mathrm{T}$-cells were sorted by negative selection using magnetic beads (Miltenyi Biotec). Cells were stimulated via CD3/CD28 (immobilized anti-CD3 and soluble anti-CD28 Abs, NA/LE, $1 \mu \mathrm{g} / \mathrm{ml}$, BD Pharmingen) in RPMI1640, $10 \% \mathrm{FBS}, 1 \%$ penicillin/streptomycin (PS). At day 2, cells were harvested, washed in warm RPMI1640 w/o FBS and PS and nuclofected with $100 \mu \mathrm{M}$ PPAR $\gamma$-specific or nontargeting (NT1) siRNA (ON-TARGETplus SMART pool, Dharmacon) using the Amaxa Human T cell Nucleofector Kit (Amaxa, Lonza) according to the manufacturer's protocol. Briefly, cells were suspended in supplemented NF solution $\left(100 \mu \mathrm{l} / 2 \times 10^{6}\right.$ cells $)$ and nucleofected using the Amaxa Nucleofector II Device and the human activated T-cell protocol (T-20). Cells $\left(2 \times 10^{6}\right.$ cells $)$ were immediately transferred into 48 -well plates containing $1 \mathrm{ml}$ of warm RPMI1640, 10\% FBS, 5 ng/ml IL-2, w/o antibiotics and cultured for $24 \mathrm{~h}$ at $37^{\circ} \mathrm{C}$. Cells were washed and exposed to replication competent HIV (NL4.3BaL, $10 \mathrm{ng} / 10^{6}$ cells) or to single round VSV-G pseudotyped HIV (HIV-VSVGGFP) strains as described above. Cells were washed and cultured up to 6 days. At $24 \mathrm{~h}, 48 \mathrm{~h}$ and $72 \mathrm{~h}$ postnucleofection, the efficiency of RNA silencing was assessed at the level of mRNA (SYBR Green real-time RT-PCR) and protein (fluorescence microscopy analysis).

\section{Cell viability and proliferation}

Magnetic bead-sorted memory $\mathrm{CD} 4^{+} \mathrm{T}$-cells were stimulated with $\mathrm{CD} 3 / \mathrm{CD} 28$ Abs for 2 days and then nuclofected with $100 \mu \mathrm{M}$ PPAR $\gamma$-specific or non-targeting (NT1) siRNA as described above. Cells were cultured in RPMI1640, 10\% FBS, $5 \mathrm{ng} / \mathrm{ml} \mathrm{IL-2,} \mathrm{w/o} \mathrm{antibiotics} \mathrm{for}$ $24 \mathrm{~h}$ at $37^{\circ} \mathrm{C}$. Cells were washed and cultured for additional 5 days. Cells were stained with the LIVE/DEAD ${ }^{\circ}$ Fixable Dead Cell Stain Kit (Aqua Vivid, Invitrogen) to exclude dead cells from analysis. Intracellular staining using Ki-67 Abs was performed to quantify proliferation of nuclofected cells. Samples were analyzed by flow cytometry. Absolute cell numbers were determined using the FlowCount fluorospheres (BeckmanCoulter).

\section{Statistics}

All statistical analyses were performed using the GraphPad Prism 5 software and details are included in Figure legends.

\section{Additional files}

Additional file 1: Figure S1. Flow cytometry sorting of Th1Th17 and Th1 cells. Total CD4 ${ }^{+}$T-cells were sorted from PBMCs by negative selection using magnetic beads (Miltenyi). Cells were labeled with a cocktail of CD45RA, CD8, CD19, CD56, CCR4, CXCR3 and CCR6 Abs in view of flow cytometry sorting. (A) Cells were selected based on their size (FSC height and wide) and granularity (SSC height and wide) to exclude debris and aggregates (P3). Memory CD4 ${ }^{+}$T-cells were then identified by their CD45RA- phenotype (P4) while excluding possible contamination by $\mathrm{CD} 8^{+} \mathrm{T}$ cells, NK cells or $\mathrm{B}$ lymphocytes using the expression of CD8, CD56 and CD19, respectively, in the same color channel (Lineage). Memory CD4 ${ }^{+} \mathrm{T}$ cells were separated by their expression of CXCR3 but not CCR4 (P5), and the expression of CCR6 identified $\mathrm{CCR}^{-} \mathrm{CXCR3}^{+}{ }^{+} \mathrm{CCR}^{+}$(Th1Th17 polarization profile) and CCR4 ${ }^{-} \mathrm{CX} \mathrm{CR}^{+}{ }^{+} \mathrm{CCR} 6$

(Th1 polarization profile). Shown values correspond to the percentages of events included in the selection window relative to single cells (P3). (B) A sample of each of the Th1Th17 and Th1 subsets was collected after cell sorting and analyzed by flow cytometry to obtain quality controls (QC).

Additional file 2: Table S1. Probe sets upregulated in Th1Th17 vs. Th1 cells. Sorted Th1Th17 and Th1 cell subsets from four HIV-uninfected donors were stimulated via CD3/CD28 for 3 days. Total RNA was extracted and reverse transcribed into CDNA to be hybridized on Human U133 Plus 2.0 including $>47,000$ probe sets per chip (Affymetrix). One-way ANOVA analysis was performed to identify differentially expressed genes ( $p$-value $<0.05$ ). Shown is the list of the 438 probe sets with a preferential expression in Th1Th17 vs. Th1, corresponding to 392 known genes and 46 unknown transcripts.

Additional file 3: Table S2. Probe sets downregulated in Th1Th17 vs. Th1 cells. Sorted Th1Th17 and Th1 cell subsets from four HIV-uninfected donors were stimulated via CD3/CD28 for 3 days. Total RNA was extracted and reverse transcribed into CDNA to be hybridized on Human U133 Plus 2.0 including $>47,000$ probe sets per chip (Affymetrix). One-way ANOVA analysis was performed to identify differentially expressed genes ( $p$-value $<0.05$ ). Shown is the list of the 342 probe sets with a preferential expression in Th1 vs. Th1Th17, corresponding to 268 known genes and 74 unknown transcripts.

Additional file 4: Figure S2. Gene Set Enrichment Analysis (GSEA) of differentially expressed in Th1Th17 vs. Th1 cells. Expression levels of the 38,113 probe sets obtained by Affymetrix were used to search the C2 Canonical pathways (A), C3 Transcription factors and miRNA (B) and C5 Gene Ontology (C) collections of the Molecular Signature DataBase (MsigDB, Broad Institute) through a GSEA. The GSEA identified several biological functions and signaling pathways differentially expressed in Th1Th17 vs. Th1 cells (FDR-value <0.05). Shown are pathways, transcription factors, and gene sets from Gene Ontology selected based on their normalized enrichment score (NES > 1.5).

Additional file 5: Figure S3. Preferential expression of the adhesion molecules CEACAM1 and MCAM on Th1Th17 vs. Th1 cells ex vivo. PBMC were stained with a cocktail of fluorochrome-labeled CD3, CD4, CD45RA, CCR4, CXCR3, CCR6, and CEACAM1 or MCAM Abs and analyzed by polychromatic flow cytometry. A viability staining (Vivid) was used to exclude dead cells. (A) Shown is the gating strategy for the identification of memory $\mathrm{CD3}^{+} \mathrm{CD}^{+}{ }^{+}$CD45RA- T-cells with a Th1Th17 (CCR6 ${ }^{+} \mathrm{CCR} 4{ }^{-} \mathrm{CXCR3}{ }^{+}$) and Th1 (CCR6CCR4-CXCR3 ${ }^{+}$) phenotype. Shown is expression of CEACAM1 (B-C) and MCAM (D-E) on Th1Th17 vs. Th1 cells. Results in $\mathbf{A}, \mathbf{B}$, and $\mathbf{D}$ are from one donor representative of results generated with cells from seven different donors. Results in $\mathbf{C}$ and $\mathbf{E}$ are statistical analysis of CEACAM1 and MCAM expression in seven different HIV-uninfected individuals. Paired $t$-Test p-values are indicated in the figures. (PDF $36 \mathrm{~kb}$ )

Additional file 6: Figure S4. Confocal microscopy quantification of PPARY protein knock down upon RNA interference. CD4 ${ }^{+}$T-cells were isolated, activated via TCR and nucleofected with PPARY vs. NT1 siRNA as described in Figure 6. At $24 \mathrm{~h}, 48 \mathrm{~h}$ and $72 \mathrm{~h}$ post-nucleofection, cells were fixed on slides and stained with PPARy Abs as in Figure 5. (A) PPARY expression was observed using fluorescence microscopy and 40x 
immersion oil objective (NA, 1.3). Shown are statistical analysis of PPARY expression at $24 \mathrm{~h}, 48 \mathrm{~h}$ and $72 \mathrm{~h}$ post-nucleofection in $\mathrm{n}=3$ different donors ( $n>100$ cells per subsets per donor). Horizontal red lines indicate median values. Unpaired $p$-values are indicated on the figures. (B) Shown is PPARY expression in cells $72 \mathrm{~h}$ after PPARy silencing from one donor representative of $\mathrm{n}=3$ donors. Images are maximum intensity $z$-projection of z-stack from one representative field per experimenta condition observed with a $63 x$ oil objective (NA, 1.46) in a LSM780 microscope (Zeiss) with an additional 2.6 numerical zoom.

Additional file 7: Figure S5. Kinetics of PPARY mRNA expression upon RNA interference. CD4 ${ }^{+}$T-cells were isolated, activated via TCR and nucleofected with PPARY vs. NT1 siRNA as described in Figure 6. Total RNA was extracted from cells at $24 \mathrm{~h}, 48 \mathrm{~h}$, and $72 \mathrm{~h}$ post-nucleofection. Levels of PPARY mRNA were quantified by real-time RT-PCR in $n=3$ different subjects relative to the internal control 285 rRNA. PPARy expression in NT1 siRNA nucleofected cells was considered $100 \%$.

Additional file 8: Figure S6. Effects of PPARY agonists on cell viability, proliferation and CD4 and CCR5 expression. Memory CD4 ${ }^{+}$T-cells from 3 healthy donors were isolated by negative selection using magnetic beads (Miltenyi), stained with CFSE $(0.5 \mu \mathrm{M})$, and stimulated via CD3/CD28 for 3 days. Cells were then cultured for three additional days with $\mathrm{IL}-2(5 \mathrm{ng} / \mathrm{ml})$ in the presence or absence of different concentrations of the PPARY agonists RGZ $(1,10,50,100 \mu M)$ and PGJ2 $(1,5,10,20,50 \mu M)$. Cells were stained with the viability dye Vivid and with CD4 and CCR5 Abs and were analyzed by polychromatic flow cytometry. (A) Shown is the gating strategy for the identification of viable cells (Vivid), CFSE ${ }^{\text {low }}$ proliferating cells, and cells expressing CD4 and CCR5, when T-cells were cultured in the absence of PPARy agonists. Depicted are results from one donor representative of results obtained with three different donors. Shown are changes induced by PPARY agonists in cell viability (B), cell proliferation (C), and the expression of CD4 and CCR5 (D-E). Depicted are the \% (left panels) and the mean fluorescence intensity (MFI) (right panels) of CFSE, CD4, and CCR5 expression. Results in B-E were generated with cells from three different donors. Horizontal lines represent median values

Additional file 9: Figure S7. Rosiglitazone triggers the nuclear translocation of PPARY. Memory $\mathrm{CD}^{+}{ }^{+}$T-cells were stimulated via CD3/CD28 for 3 days and cultured in the presence or absence of the PPARY agonist RGZ $(50 \mu \mathrm{M})$ and/or the antagonist T007907 $(10 \mu \mathrm{M})$ for $20 \mathrm{~h}$ at $37^{\circ} \mathrm{C}$. Cells were seeded on poly-L-lysine-coated 8-well glass culture slides and stained intracellularly for PPARY, as described in Material and Methods. Slides were mounted with the ProLong Gold Antifade reagent containing the nuclear dye DAPI. Slides were observed by confocal microscopy (Carl Zeiss). (A) Shown are images taken using the AxioVision 4.8.2 software at 100x oil magnification and z-stack reconstruction of $0.2 \mu \mathrm{m}$ virtual sections. (B) Shown are statistical analysis of the nuclear vs. cytoplasm ratio of PPARY expression in cells treated or not with RGZ and/or T007907 performed with the ImageJ software $(\mathrm{NIH})$ on $n=15$ cells per condition. Unpaired $t$-Test $\mathrm{p}$-values are indicated on the graph. Results in $\mathbf{A}-\mathbf{B}$ are from one donor, representative of results observed with cells from four different donors.

\section{Competing interests}

The authors declare that they have no competing interests.

\section{Authors' contributions}

$A B, A C B$, and $Y Z$ performed the majority of experiments and contributed to figure design and manuscript writing. JPG performed statistical analysis of microarray data. PM sorted the cells and extracted the RNA for microarrays and contributed to the validation of results by RT-PCR. AG and SDF performed real-time PCR analysis. VSW contributed to cell sorting. MAJ, JPR and CT were involved in sample collection and experimental design. PA designed the study, designed the figures, and wrote the manuscript. All authors read and approved the manuscript.

\section{Acknowledgements}

The authors thank Mrs. L. Lejeune and Dr. D. Gauchat (Flow Cytometry Core Facility, CHUM-Research Center, Saint-Luc Hospital, Montréal, QC, Canada) for expert technical support with flow cytometry analysis and sorting, Mrs. A. Vassal for help with ethical approvals and informed consents, Dr. M-R.
Boulassel, Mr. M. Legault, and Mrs. V. Lafontaine for sample management, and Dr. C. Aiken, Dr. D. Gabuzda, Dr. J. Pomerantz, and Dr. M. Trembay for their gift of HIV plasmids. The authors also thank Ms. M. Savall for ELISA assays, Drs. N. Chomont and M. El-Far for critical reading of the manuscript and valuable discussions. Finally, the authors acknowledge human donors for their precious gift of leukapheresis essential to this work.

This work was supported in part by grants from the Canadian Institutes of Health Research (CIHR) (MOP-82849; MOP-114957), Fondation du CHUM, Fonds de Recherche du Québec-Santé (FRQ-S), the French Institut National de la Santé et de la Recherche Médicale (INSERM), Agence Nationale de Recherche sur le SIDA (ANRS) and Fondation de France to PA; and infrastructure funding from the Canadian Foundation for Innovation to $C T$ and PA. This work was also supported in part by the CIHR (grant \#103230), the CIHR Canadian HIV Trials Network (CTN \#247), the FRQ-S/AIDS and Infectious Diseases Network, Québec, Canada. PA was supported by New Investigator Awards from FRQ-S and INSERM. PM was supported by Postdoctoral Fellowships from the ANRS and FRQ-S. VSW was supported by a CIHR Doctoral Fellowship. MAJ is supported by a CANFAR/CTN Postdoctoral Fellowship Award. JPR holds a Louis Lowenstein Chair in Hematology and Oncology, McGill University. $\mathrm{CT}$ is a FRQ-S Scholar and holds a Pfizer/Université de Montréal Chair in HIV translational research. Core facilities were supported by the Fondation du CHUM and the FRQ-S/AIDS and Infectious Diseases Network. The new affiliation for AB is McGill University, Montréal, Qc, Canada.

\section{Author details}

${ }^{1}$ Department of Microbiology, Infectiology, and Immunology, Université de Montréal, Faculty of Medicine, Montreal, Quebec, Canada. ${ }^{2} \mathrm{CHUM}$-Research Centre, 900 rue Saint-Denis, Tour Viger, room R09.416, Montréal, Quebec H2X OA9, Canada. ${ }^{3}$ Faculty of Medicine, CARTaGENE, Université de Montréal, Montreal, Quebec, Canada. ${ }^{4}$ Department of Pediatrics, Faculty of Medicine, Ste Justine Hospital Research Center, Université de Montréal, Montreal, Quebec, Canada. ${ }^{5}$ Chronic Viral IIIness Service, McGill University Health Centre, Montreal, Quebec, Canada. ${ }^{6}$ Research Institute, McGill University Health Centre, Montreal, Quebec, Canada. ${ }^{7}$ Division of Hematology, McGill University Health Centre, Montreal, Quebec, Canada.

Received: 29 August 2013 Accepted: 10 December 2013 Published: 21 December 2013

\section{References}

1. Trono D, Van Lint C, Rouzioux C, Verdin E, Barre-Sinoussi F, Chun TW, Chomont $\mathrm{N}$ : HIV persistence and the prospect of long-term drug-free remissions for HIV-infected individuals. Science 2010, 329:174-180.

2. Deeks SG, Autran B, Berkhout B, Benkirane M, Cairns S, Chomont N, Chun TW, Churchill M, Di Mascio M, Katlama C, et al: Towards an HIV cure: a global scientific strategy. Nat Rev Immunol 2012, 12:607-614.

3. Eisele E, Siliciano RF: Redefining the viral reservoirs that prevent HIV-1 eradication. Immunity 2012, 37:377-388.

4. Katlama C, Deeks SG, Autran B, Martinez-Picado J, van Lunzen J, Rouzioux C, Miller M, Vella S, Schmitz JE, Ahlers J, et al: Barriers to a cure for HIV: new ways to target and eradicate HIV-1 reservoirs. Lancet 2013, 381:2109-2117.

5. Sant AJ, McMichael A: Revealing the role of CD4(+) T cells in viral immunity. J Exp Med 2012, 209:1391-1395.

6. Chomont N, El-Far M, Ancuta P, Trautmann L, Procopio FA, Yassine-Diab B, Boucher G, Boulassel MR, Ghattas G, Brenchley JM, et al: HIV reservoir size and persistence are driven by $\mathrm{T}$ cell survival and homeostatic proliferation. Nat Med 2009, 15:893-900.

7. Blanco-Melo D, Venkatesh S, Bieniasz PD: Intrinsic cellular defenses against human immunodeficiency viruses. Immunity 2012, 37:399-411.

8. Sheehy AM, Gaddis NC, Choi JD, Malim MH: Isolation of a human gene that inhibits HIV-1 infection and is suppressed by the viral Vif protein. Nature 2002, 418:646-650.

9. Harris RS, Bishop KN, Sheehy AM, Craig HM, Petersen-Mahrt SK, Watt IN, Neuberger MS, Malim MH: DNA deamination mediates innate immunity to retroviral infection. Cell 2003, 113:803-809.

10. Mehle A, Strack B, Ancuta P, Zhang C, McPike M, Gabuzda D: Vif overcomes the innate antiviral activity of APOBEC3G by promoting its degradation in the ubiquitin-proteasome pathway. J Biol Chem 2004, 279:7792-7798. 
11. Stremlau M, Owens CM, Perron MJ, Kiessling M, Autissier P, Sodroski J: The cytoplasmic body component TRIM5alpha restricts HIV-1 infection in old world monkeys. Nature 2004, 427:848-853.

12. Stremlau M, Perron M, Lee M, Li Y, Song B, Javanbakht H, Diaz-Griffero F, Anderson DJ, Sundquist WI, Sodroski J: Specific recognition and accelerated uncoating of retroviral capsids by the TRIM5alpha restriction factor. Proc Natl Acad Sci U S A 2006, 103:5514-5519.

13. Neil SJ, Zang T, Bieniasz PD: Tetherin inhibits retrovirus release and is antagonized by HIV-1 Vpu. Nature 2008, 451:425-430.

14. Laguette $N$, Sobhian B, Casartelli N, Ringeard M, Chable-Bessia C, Segeral E, Yatim A, Emiliani S, Schwartz O, Benkirane M: SAMHD1 is the dendritic- and myeloid-cell-specific HIV-1 restriction factor counteracted by Vpx. Nature 2011, 474:654-657.

15. Hrecka K, Hao C, Gierszewska M, Swanson SK, Kesik-Brodacka M, Srivastava S, Florens L, Washburn MP, Skowronski J: Vpx relieves inhibition of HIV-1 infection of macrophages mediated by the SAMHD1 protein. Nature 2011, 474:658-661.

16. Bergamaschi A, David A, Le Rouzic E, Nisole S, Barre-Sinoussi F, Pancino G: The CDK inhibitor p21Cip1/WAF1 is induced by FcgammaR activation and restricts the replication of human immunodeficiency virus type 1 and related primate lentiviruses in human macrophages. J Virol 2009, 83:12253-12265.

17. Chen H, Li C, Huang J, Cung T, Seiss K, Beamon J, Carrington MF, Porter LC, Burke PS, Yang Y, et al: CD4+ T cells from elite controllers resist HIV-1 infection by selective upregulation of p21. J Clin Invest 2011, 121:1549-1560.

18. Saez-Cirion A, Hamimi C, Bergamaschi A, David A, Versmisse P, Melard A, Boufassa F, Barre-Sinoussi F, Lambotte O, Rouzioux C, Pancino G: Restriction of HIV-1 replication in macrophages and CD4+ T cells from HIV controllers. Blood 2011, 118:955-964.

19. Berger EA, Doms RW, Fenyo EM, Korber BT, Littman DR, Moore JP, Sattentau QJ, Schuitemaker H, Sodroski J, Weiss RA: A new classification for HIV-1. Nature 1998, 391:240

20. Gorry PR, Ancuta P: Coreceptors and HIV-1 pathogenesis. Curr HIV/AIDS Rep 2011, 8:45-53.

21. Brass AL, Dykxhoorn DM, Benita Y, Yan N, Engelman A, Xavier RJ, Lieberman $J$, Elledge SJ: Identification of host proteins required for HIV infection through a functional genomic screen. Science 2008, 319:921-926.

22. Zhou H, Xu M, Huang Q, Gates AT, Zhang XD, Castle JC, Stec E, Ferrer M, Strulovici B, Hazuda DJ, Espeseth AS: Genome-scale RNAi screen for host factors required for HIV replication. Cell Host Microbe 2008, 4:495-504.

23. Konig R, Zhou Y, Elleder D, Diamond TL, Bonamy GM, Irelan JT, Chiang CY, Tu BP, De Jesus PD, Lilley CE, et al: Global analysis of host-pathogen interactions that regulate early-stage HIV-1 replication. Cell 2008, 135:49-60.

24. Yeung ML, Houzet L, Yedavalli VS, Jeang KT: A genome-wide short hairpin RNA screening of jurkat T-cells for human proteins contributing to productive HIV-1 replication. J Biol Chem 2009, 284:19463-19473.

25. Bushman FD, Malani N, Fernandes J, D'Orso I, Cagney G, Diamond TL, Zhou $H$, Hazuda DJ, Espeseth AS, Konig R, et al: Host cell factors in HIV replication: meta-analysis of genome-wide studies. PLoS Pathog 2009, 5:e1000437.

26. Goff SP: Knockdown screens to knockout HIV-1. Cell 2008, 135:417-420.

27. Sallusto F, Lanzavecchia A: Heterogeneity of CD4+ memory T cells: functional modules for tailored immunity. Eur J Immunol 2009, 39:2076-2082

28. Ancuta P, Monteiro P, Sekaly RP: Th17 lineage commitment and HIV-1 pathogenesis. Curr Opin HIV AIDS 2010, 5:158-165.

29. Rivino L, Messi M, Jarrossay D, Lanzavecchia A, Sallusto F, Geginat J: Chemokine receptor expression identifies Pre-T helper (Th)1, Pre-Th2, and nonpolarized cells among human CD4+ central memory T cells. J Exp Med 2004, 200:725-735.

30. Acosta-Rodriguez EV, Rivino L, Geginat J, Jarrossay D, Gattorno M, Lanzavecchia A, Sallusto F, Napolitani G: Surface phenotype and antigenic specificity of human interleukin 17-producing $T$ helper memory cells. Nat Immunol 2007, 8:639-646.

31. Gosselin A, Monteiro P, Chomont N, Diaz-Griffero F, Said EA, Fonseca S, Wacleche V, El-Far M, Boulassel MR, Routy JP, et al: Peripheral blood CCR4+ CCR6+ and CXCR3+ CCR6+ CD4+ T cells are highly permissive to HIV-1 infection. J Immunol 2010, 184:1604-1616.

32. Casazza JP, Brenchley JM, Hill BJ, Ayana R, Ambrozak D, Roederer M, Douek DC, Betts MR, Koup RA: Autocrine production of beta-chemokines protects CMV-Specific CD4 T cells from HIV infection. PLoS Pathog 2009, 5:e1000646.
33. Geldmacher C, Ngwenyama N, Schuetz A, Petrovas C, Reither K, Heeregrave EJ, Casazza JP, Ambrozak DR, Louder M, Ampofo W, et al: Preferential infection and depletion of Mycobacterium tuberculosis-specific CD4 T cells after HIV-1 infection. J Exp Med 2010, 207:2869-2881.

34. Geldmacher C, Schuetz A, Ngwenyama N, Casazza JP, Sanga E, Saathoff E, Boehme C, Geis S, Maboko L, Singh M, et al: Early depletion of Mycobacterium tuberculosis-specific T helper 1 cell responses after HIV-1 infection. J Infect Dis 2008, 198:1590-1598.

35. Sacre K, Hunt PW, Hsue PY, Maidji E, Martin JN, Deeks SG, Autran B, McCune $\mathrm{JM}$ : A role for cytomegalovirus-specific CD4 + CX3CR1+ T cells and cytomegalovirus-induced T-cell immunopathology in HIV-associated atherosclerosis. AIDS 2012, 26:805-814.

36. Hu H, Nau M, Ehrenberg P, Chenine AL, Macedo C, Zhou Y, Daye ZJ, Wei Z, Vahey M, Michael NL, et al: Distinct gene-expression profiles associated with the susceptibility of pathogen-specific CD4 T cells to HIV-1 infection. Blood 2013, 121:1136-1144

37. Ancuta P, Autissier P, Wurcel A, Zaman T, Stone D, Gabuzda D: CD16+ monocyte-derived macrophages activate resting T cells for HIV infection by producing CCR3 and CCR4 ligands. J Immunol 2006, 176:5760-5771.

38. Ancuta P, Kunstman KJ, Autissier P, Zaman T, Stone D, Wolinsky SM, Gabuzda D: CD16+ monocytes exposed to HIV promote highly efficient viral replication upon differentiation into macrophages and interaction with T cells. Virology 2006, 344:267-276.

39. Sallusto F, Lenig D, Forster R, Lipp M, Lanzavecchia A: Two subsets of memory $T$ lymphocytes with distinct homing potentials and effector functions. Nature 1999, 401:708-712.

40. Riou C, Yassine-Diab B, Van Grevenynghe J, Somogyi R, Greller LD, Gagnon D, Gimmig S, Wilkinson P, Shi Y, Cameron MJ, et al: Convergence of TCR and cytokine signaling leads to FOXO3a phosphorylation and drives the survival of CD4+ central memory T cells. J Exp Med 2007, 204:79-91.

41. Subramanian A, Tamayo P, Mootha VK, Mukherjee S, Ebert BL, Gillette MA, Paulovich A, Pomeroy SL, Golub TR, Lander ES, Mesirov JP: Gene set enrichment analysis: a knowledge-based approach for interpreting genome-wide expression profiles. Proc Natl Acad Sci U S A 2005, 102:15545-15550.

42. Imbeault M, Giguere K, Ouellet M, Tremblay MJ: Exon level transcriptomic profiling of HIV-1-infected CD4(+) T cells reveals virus-induced genes and host environment favorable for viral replication. PLoS Pathog 2012, 8:e1002861

43. Espert L, Degols G, Lin YL, Vincent T, Benkirane M, Mechti N: Interferon-induced exonuclease ISG20 exhibits an antiviral activity against human immunodeficiency virus type 1. J Gen Virol 2005, 86:2221-2229.

44. de Beaucoudrey L, Puel A, Filipe-Santos O, Cobat A, Ghandil P, Chrabieh M, Feinberg J, von Bernuth $H$, Samarina A, Janniere L, et al: Mutations in STAT3 and IL12RB1 impair the development of human IL-17-producing T cells. J Exp Med 2008, 205:1543-1550.

45. Wang C, Hayashi H, Harrison R, Chiu B, Chan JR, Ostergaard HL, Inman RD, Jongstra J, Cybulsky Ml, Jongstra-Bilen J: Modulation of Mac-1 (CD11b/ CD18)-mediated adhesion by the leukocyte-specific protein 1 is key to its role in neutrophil polarization and chemotaxis. J Immunol 2002, 169:415-423.

46. Korn T, Bettelli E, Oukka M, Kuchroo VK: IL-17 and Th17 Cells. Annu Rev Immunol 2009, 27:485-517.

47. Lee Y, Awasthi A, Yosef N, Quintana FJ, Xiao S, Peters A, Wu C, Kleinewietfeld M, Kunder S, Hafler DA, et al: Induction and molecular signature of pathogenic TH17 cells. Nat Immunol 2012, 13:991-999.

48. Ivanov II, McKenzie BS, Zhou L, Tadokoro CE, Lepelley A, Lafaille JJ, Cua DJ, Littman DR: The orphan nuclear receptor RORgammat directs the differentiation program of proinflammatory IL-17+ T helper cells. Cell 2006, 126:1121-1133.

49. Zhou L, Littman DR: Transcriptional regulatory networks in Th17 cell differentiation. Curr Opin Immunol 2009, 21:146-152.

50. Weng $L$, Brown J, Eng C: PTEN induces apoptosis and cell cycle arrest through phosphoinositol-3-kinase/Akt-dependent and -independent pathways. Hum Mol Genet 2001, 10:237-242.

51. Yoshimura A, Muto G: TGF-beta function in immune suppression. Curr Top Microbiol Immunol 2011, 350:127-147.

52. Yagi R, Zhu J, Paul WE: An updated view on transcription factor GATA3-mediated regulation of Th1 and Th2 cell differentiation. Int Immunol 2011, 23:415-420. 
53. Ryan RF, Schultz DC, Ayyanathan K, Singh PB, Friedman JR, Fredericks WJ, Rauscher FJ 3rd: KAP-1 corepressor protein interacts and colocalizes with heterochromatic and euchromatic HP1 proteins: a potential role for Kruppel-associated box-zinc finger proteins in heterochromatinmediated gene silencing. Mol Cell Biol 1999, 19:4366-4378.

54. Gommans WM, Haisma HJ, Rots MG: Engineering zinc finger protein transcription factors: the therapeutic relevance of switching endogenous gene expression on or off at command. J Mol Biol 2005, 354:507-519.

55. Gorska MM, Liang Q, Stafford SJ, Goplen N, Dharajiya N, Guo L, Sur S, Gaestel M, Alam R: MK2 controls the level of negative feedback in the NF-kappaB pathway and is essential for vascular permeability and airway inflammation. J Exp Med 2007, 204:1637-1652.

56. Gloerich M, Bos JL: Epac: defining a new mechanism for CAMP action. Annu Rev Pharmacol Toxicol 2010, 50:355-375.

57. Puca R, Nardinocchi L, Givol D, D'Orazi G: Regulation of p53 activity by HIPK2: molecular mechanisms and therapeutical implications in human cancer cells. Oncogene 2010, 29:4378-4387.

58. Sorriento D, Ciccarelli M, Santulli G, Campanile A, Altobelli GG, Cimini V, Galasso G, Astone D, Piscione F, Pastore L, et al: The G-protein-coupled receptor kinase 5 inhibits NFkappaB transcriptional activity by inducing nuclear accumulation of IkappaB alpha. Proc Natl Acad Sci U S A 2008, 105:17818-17823.

59. Valanne S, Myllymaki H, Kallio J, Schmid MR, Kleino A, Murumagi A, Airaksinen L, Kotipelto T, Kaustio M, Ulvila J, et al: Genome-wide RNA interference in Drosophila cells identifies $G$ protein-coupled receptor kinase 2 as a conserved regulator of NF-kappaB signaling. J Immunol 2010, 184:6188-6198.

60. Channavajhala PL, Rao VR, Spaulding V, Lin LL, Zhang YG: hKSR-2 inhibits MEKK3-activated MAP kinase and NF-kappaB pathways in inflammation. Biochem Biophys Res Commun 2005, 334:1214-1218.

61. Cosmi L, De Palma R, Santarlasci V, Maggi L, Capone M, Frosali F, Rodolico G, Querci V, Abbate G, Angeli R, et al: Human interleukin 17-producing cells originate from a CD161 + CD4+ T cell precursor. J Exp Med 2008, 205:1903-1916.

62. Matloubian M, David A, Engel S, Ryan JE, Cyster JG: A transmembrane CXC chemokine is a ligand for HIV-coreceptor Bonzo. Nat Immunol 2000, 1:298-304.

63. Unutmaz D, Xiang W, Sunshine MJ, Campbell J, Butcher E, Littman DR: The primate lentiviral receptor Bonzo/STRL33 is coordinately regulated with CCR5 and its expression pattern is conserved between human and mouse. J Immunol 2000, 165:3284-3292.

64. Potula R, Ramirez SH, Knipe B, Leibhart J, Schall K, Heilman D, Morsey B, Mercer A, Papugani A, Dou H, Persidsky Y: Peroxisome proliferator-activated receptor-gamma activation suppresses HIV-1 replication in an animal model of encephalitis. AIDS 2008, 22:1539-1549.

65. Prost S, Le Dantec M, Auge S, Le Grand R, Derdouch S, Auregan G, Deglon $N$, Relouzat $F$, Aubertin AM, Maillere $B$, et al: Human and simian immunodeficiency viruses deregulate early hematopoiesis through a Nef/PPARgamma/STAT5 signaling pathway in macaques. J Clin Invest 2008, 118:1765-1775.

66. Skolnik PR, Rabbi MF, Mathys JM, Greenberg AS: Stimulation of peroxisome proliferator-activated receptors alpha and gamma blocks HIV-1 replication and TNFalpha production in acutely infected primary blood cells, chronically infected U1 cells, and alveolar macrophages from HIV-infected subjects. J Acquir Immune Defic Syndr 2002, 31:1-10

67. Cicala C, Arthos J, Rubbert A, Selig S, Wildt K, Cohen OJ, Fauci AS: HIV-1 envelope induces activation of caspase- 3 and cleavage of focal adhesion kinase in primary human CD4(+) T cells. Proc Natl Acad Sci U S A 2000, 97:1178-1183

68. Cicala C, Arthos J, Ruiz M, Vaccarezza M, Rubbert A, Riva A, Wildt K, Cohen $O$, Fauci AS: Induction of phosphorylation and intracellular association of CC chemokine receptor 5 and focal adhesion kinase in primary human CD4+ T cells by macrophage-tropic HIV envelope. J Immunol 1999, 163:420-426.

69. Zhang X, Brunner T, Carter L, Dutton RW, Rogers P, Bradley L, Sato T, Reed JC, Green D, Swain SL: Unequal death in T helper cell (Th)1 and Th2 effectors: Th1, but not Th2, effectors undergo rapid Fas/FasL-mediated apoptosis. J Exp Med 1997, 185:1837-1849.

70. Zhou YW, Komada Y, Inaba H, Azuma E, Sakurai M: Down-regulation of Fas-associated phosphatase-1 (FAP-1) in interleukin-2-activated T cells. Cell Immunol 1998, 186:103-110.
71. Freiss $G$, Chalbos D: PTPN13/PTPL1: an important regulator of tumor aggressiveness. Anticancer Agents Med Chem 2011, 11:78-88.

72. Yang J, Zhu H, Murphy TL, Ouyang W, Murphy KM: IL-18-stimulated GADD45 beta required in cytokine-induced, but not TCR-induced, IFN-gamma production. Nat Immunol 2001, 2:157-164

73. Chi H, Lu B, Takekawa M, Davis RJ, Flavell RA: GADD45beta/ GADD45gamma and MEKK4 comprise a genetic pathway mediating STAT4-independent IFNgamma production in T cells. Embo J 2004, 23:1576-1586

74. Sapkota GP: The TGFbeta-induced phosphorylation and activation of p38 mitogen-activated protein kinase is mediated by MAP3K4 and MAP3K10 but not TAK1. Open Biol 2013, 3:130067.

75. Campi G, Crosti M, Consogno G, Facchinetti V, Conti-Fine BM, Longhi R, Casorati G, Dellabona P, Protti MP: CD4(+) T cells from healthy subjects and colon cancer patients recognize a carcinoembryonic antigen-specific immunodominant epitope. Cancer Res 2003, 63:8481-8486.

76. Boulton IC, Gray-Owen SD: Neisserial binding to CEACAM1 arrests the activation and proliferation of CD4+ T lymphocytes. Nat Immunol 2002, 3:229-236.

77. Kamiyama T, Watanabe H, lijima M, Miyazaki A, Iwamoto S: Coexpression of CCR6 and CD146 (MCAM) is a marker of effector memory T-helper 17 cells. J Dermatol 2012, 39:838-842.

78. Larochelle C, Cayrol R, Kebir H, Alvarez Jl, Lecuyer MA, Ifergan I, Viel E, Bourbonniere L, Beauseigle D, Terouz S, et al: Melanoma cell adhesion molecule identifies encephalitogenic $T$ lymphocytes and promotes their recruitment to the central nervous system. Brain 2012, 135:2906-2924.

79. Klotz L, Burgdorf S, Dani I, Saijo K, Flossdorf J, Hucke S, Alferink J, Nowak N, Beyer M, Mayer G, et al: The nuclear receptor PPAR gamma selectively inhibits Th17 differentiation in a T cell-intrinsic fashion and suppresses CNS autoimmunity. J Exp Med 2009, 206:2079-2089.

80. Zhang MA, Rego D, Moshkova M, Kebir H, Chruscinski A, Nguyen $H$, Akkermann R, Stanczyk FZ, Prat A, Steinman L, Dunn SE: Peroxisome proliferator-activated receptor (PPAR)alpha and -gamma regulate IFNgamma and IL-17A production by human T cells in a sex-specific way. Proc Natl Acad Sci U S A 2012, 109:9505-9510.

81. Lee G, Elwood F, McNally J, Weiszmann J, Lindstrom M, Amaral K, Nakamura M, Miao S, Cao P, Learned RM, et al: T0070907, a selective ligand for peroxisome proliferator-activated receptor gamma, functions as an antagonist of biochemical and cellular activities. J Biol Chem 2002, 277:19649-19657.

82. Hiscott J, Kwon H, Genin P: Hostile takeovers: viral appropriation of the NF-kappaB pathway. J Clin Invest 2001, 107:143-151

83. Wang C, Kang SG, Lee J, Sun Z, Kim CH: The roles of CCR6 in migration of Th17 cells and regulation of effector T-cell balance in the gut. Mucosal Immunol 2009, 2:173-183.

84. Reboldi A, Coisne C, Baumjohann D, Benvenuto F, Bottinelli D, Lira S, Uccelli A, Lanzavecchia A, Engelhardt B, Sallusto F: C-C chemokine receptor 6-regulated entry of $\mathrm{TH}-17$ cells into the CNS through the choroid plexus is required for the initiation of EAE. Nat Immunol 2009, 10:514-523.

85. Malpass K: Disease mechanisms in MS: Cell adhesion molecule MCAM on pathogenic T cells-a green light for CNS entry in multiple sclerosis. Nat Rev Neurol 2012, 8:592.

86. Sato W, Aranami T, Yamamura T: Cutting edge: human Th17 cells are identified as bearing CCR2 + CCR5- phenotype. J Immunol 2007, 178:7525-7529.

87. O'Brien SJ, Moore JP: The effect of genetic variation in chemokines and their receptors on HIV transmission and progression to AIDS. Immunol Rev 2000, 177:99-111.

88. Gonzalez E, Rovin BH, Sen L, Cooke G, Dhanda R, Mummidi S, Kulkarni H, Bamshad MJ, Telles V, Anderson SA, et al: HIV-1 infection and AIDS dementia are influenced by a mutant MCP-1 allele linked to increased monocyte infiltration of tissues and MCP-1 levels. Proc Natl Acad Sci U S A 2002, 99:13795-13800.

89. Dunfee R, Thomas ER, Gorry PR, Wang J, Ancuta P, Gabuzda D: Mechanisms of HIV-1 neurotropism. Curr HIV Res 2006, 4:267-278.

90. Chen L, Chen Z, Baker K, Halvorsen EM, da Cunha AP, Flak MB, Gerber G, Huang $\mathrm{YH}$, Hosomi S, Arthur JC, et al: The short isoform of the CEACAM1 receptor in intestinal T cells regulates mucosal immunity and homeostasis via Tfh cell induction. Immunity 2012, 37:930-946.

91. Douek DC, Roederer M, Koup RA: Emerging concepts in the immunopathogenesis of AIDS. Annu Rev Med 2009, 60:471-484. 
92. Limou S, Coulonges C, Herbeck JT, van Manen D, An P, Le Clerc S, Delaneau $\mathrm{O}$, Diop G, Taing L, Montes $M$, et al: Multiple-cohort genetic association study reveals CXCR6 as a new chemokine receptor involved in long-term nonprogression to AIDS. J Infect Dis 2010, 202:908-915.

93. Bazan JF, Bacon KB, Hardiman G, Wang W, Soo K, Rossi D, Greaves DR, Zlotnik A, Schall TJ: A new class of membrane-bound chemokine with a CX3C motif. Nature 1997, 385:640-644.

94. Blanchet F, Moris A, Mitchell JP, Piguet V: A look at HIV journey: from dendritic cells to infection spread in CD4(+) T cells. Curr Opin HIV AIDS 2011, 6:391-397.

95. Ancuta P, Liu KY, Misra V, Wacleche VS, Gosselin A, Zhou X, Gabuzda D: Transcriptional profiling reveals developmental relationship and distinct biological functions of CD16+ and CD16- monocyte subsets. BMC Genomics 2009, 10:403

96. Ziegler-Heitbrock L, Ancuta P, Crowe S, Dalod M, Grau V, Hart DN, Leenen PJ, Liu YJ, Macpherson G, Randolph GJ, et al: Nomenclature of monocytes and dendritic cells in blood. Blood 2010, 116(16):74-80.

97. Ellery PJ, Tippett E, Chiu YL, Paukovics G, Cameron PU, Solomon A, Lewin SR, Gorry PR, Jaworowski A, Greene WC, et al: The CD16+ monocyte subset is more permissive to infection and preferentially harbors HIV-1 in vivo. $\mathrm{J}$ Immunol 2007, 178:6581-6589.

98. Kumar V, Prakash O, Manpreet S, Sumedh G, Medhi B: Genetic basis of HIV-1 resistance and susceptibility: an approach to understand correlation between human genes and HIV-1 infection. Indian J Exp Biol 2006, 44:683-692.

99. Colonna M: Cytolytic responses: cadherins put out the fire. J Exp Med 2006, 203:261-264

100. Casazza JP, Betts MR, Price DA, Precopio ML, Ruff LE, Brenchley JM, Hill BJ, Roederer M, Douek DC, Koup RA: Acquisition of direct antiviral effector functions by CMV-specific CD4+ T lymphocytes with cellular maturation. J Exp Med 2006, 203:2865-2877

101. Streeck H, Kwon DS, Pyo A, Flanders M, Chevalier MF, Law K, Julg B, Trocha K, Jolin JS, Anahtar MN, et al: Epithelial adhesion molecules can inhibit HIV-1-specific CD8(+) T-cell functions. Blood 2011, 117:5112-5122.

102. Lazarevic V, Chen X, Shim JH, Hwang ES, Jang E, Bolm AN, Oukka M, Kuchroo VK, Glimcher LH: T-bet represses $T(H) 17$ differentiation by preventing Runx1-mediated activation of the gene encoding RORgammat. Nat Immunol 2011, 12:96-104.

103. Chuang HC, Wang JM, Hsieh WC, Chang Y, Su IJ: Up-regulation of activating transcription factor- 5 suppresses SAP expression to activate $T$ cells in hemophagocytic syndrome associated with Epstein-Barr virus infection and immune disorders. Am J Pathol 2008, 173:1397-1405.

104. Li MD, Li CM, Wang Z: The role of circadian clocks in metabolic disease. Yale J Biol Med 2012, 85:387-401.

105. Lawrence T, Natoli G: Transcriptional regulation of macrophage polarization: enabling diversity with identity. Nat Rev Immunol 2011, 11:750-761.

106. Glass CK, Saijo K: Nuclear receptor transrepression pathways that regulate inflammation in macrophages and T cells. Nat Rev Immunol 2010, 10:365-376.

107. Klotz L, Knolle P: Nuclear receptors: TH17 cell control from within. FEBS Lett 2011, 585:3764-3769.

108. Yin KJ, Fan Y, Hamblin M, Zhang J, Zhu T, Li S, Hawse JR, Subramaniam M, Song CZ, Urrutia R, et al: KLF11 mediates PPARgamma cerebrovascular protection in ischaemic stroke. Brain 2013, 136:1274-1287.

109. Manel N, Unutmaz D, Littman DR: The differentiation of human $\mathrm{T}(\mathrm{H})-17$ cells requires transforming growth factor-beta and induction of the nuclear receptor RORgammat. Nat Immunol 2008, 9:641-649.

110. Brugnano JL, Chan BK, Seal BL, Panitch A: Cell-penetrating peptides can confer biological function: regulation of inflammatory cytokines in human monocytes by MK2 inhibitor peptides. J Control Release 2011 155:128-133.

111. Furler RL, Uittenbogaart $\mathrm{CH}$ : Signaling through the P38 and ERK pathways: a common link between HIV replication and the immune response. Immunol Res 2010, 48:99-109.

112. Cheng Y, Geng H, Cheng SH, Liang P, Bai Y, Li J, Srivastava G, Ng MH, Fukagawa T, Wu X, et al: KRAB zinc finger protein ZNF382 is a proapoptotic tumor suppressor that represses multiple oncogenes and is commonly silenced in multiple carcinomas. Cancer Res 2010, 70:6516-6526.

113. Hanley TM, Blay Puryear W, Gummuluru S, Viglianti GA: PPARgamma and LXR signaling inhibit dendritic cell-mediated HIV-1 capture and trans-infection. PLoS Pathog 2010, 6:e1000981.
114. Boisvert M, Cote S, Vargas A, Pasvanis S, Bounou S, Barbeau B, Dumais N PGJ2 antagonizes NF-kappaB-induced HIV-1 LTR activation in colonic epithelial cells. Virology 2008, 380:1-11.

115. Willermain F, Dulku S, Gonzalez NS, Blero D, Driessens G, De Graef C, Caspers L, Bruyns C: 15-Deoxy-12,14-prostaglandin J2 inhibits interferon gamma induced MHC class II but not class I expression on ARPE cells through a PPAR gamma independent mechanism. Prostaglandins Other Lipid Mediat 2006, 80:136-143.

116. Jadhav A, Niesen FH, Schultz L, Oppermann U, Maloney DJ, Simeonov A: Potent and selective inhibitors of NAD + -dependent 15-hydroxyprostaglandin dehydrogenase (HPGD). Bethesda, US: Probe Reports from the NIH Molecular Libraries Program; 2010.

117. Thompson PW, Bayliffe Al, Warren AP, Lamb JR: Interleukin-10 is upregulated by nanomolar rosiglitazone treatment of mature dendritic cells and human CD4+ T cells. Cytokine 2007, 39:184-191.

118. Castrillo A, Tontonoz P: Nuclear receptors in macrophage biology: at the crossroads of lipid metabolism and inflammation. Annu Rev Cell Dev Biol 2004, 20:455-480.

119. Ladias JA: Convergence of multiple nuclear receptor signaling pathways onto the long terminal repeat of human immunodeficiency virus-1. J Biol Chem 1994, 269:5944-5951.

120. Hurst T: Conservation of the nuclear receptor response element in HIV-1 LTRs: a possible PPAR response element? ISRN Virology 2013, 2013:1-11. ID609348.

121. Cariou B, Charbonnel B, Staels B: Thiazolidinediones and PPARgamma agonists: time for a reassessment. Trends Endocrinol Metab 2012, 23:205-215

122. Lake JE, Tseng $\mathrm{CH}$, Currier JS: A pilot study of telmisartan for visceral adiposity in HIV infection: the metabolic abnormalities, telmisartan, and HIV infection (MATH) trial. PLoS One 2013, 8:e58135.

123. Boulassel MR, Spurll G, Rouleau D, Tremblay C, Edwardes M, Sekaly RP, Lalonde R, Routy JP: Changes in immunological and virological parameters in HIV-1 infected subjects following leukapheresis. J Clin Apher 2003, 18:55-60.

124. Roederer M: Compensation in flow cytometry. Curr Protoc Cytom 2002 22:1.14.1-1.14.20. Chapter 1:Unit 114

125. Monteiro P, Gosselin A, Wacleche VS, El-Far M, Said EA, Kared H, Grandvaux N, Boulassel MR, Routy JP, Ancuta P: Memory CCR6 + CD4+ T cells are preferential targets for productive HIV type 1 infection regardless of their expression of integrin beta7. J Immunol 2011, 186:4618-4630.

126. Gentleman RC, Carey VJ, Bates DM, Bolstad B, Dettling M, Dudoit S, Ellis B, Gautier L, Ge Y, Gentry J, et al: Bioconductor: open software development for computational biology and bioinformatics. Genome Biol 2004, 5:R80.

127. Irizarry RA, Hobbs B, Collin F, Beazer-Barclay YD, Antonellis KJ, Scherf U, Speed TP: Exploration, normalization, and summaries of high density oligonucleotide array probe level data. Biostatistics 2003, 4:249-264.

128. Hackstadt AJ, Hess AM: Filtering for increased power for microarray data analysis. BMC Bioinforma 2009, 10:11.

129. Chaussabel D, Quinn C, Shen J, Patel P, Glaser C, Baldwin N, Stichweh D, Blankenship D, Li L, Munagala I, et al: A modular analysis framework for blood genomics studies: application to systemic lupus erythematosus. Immunity 2008, 29:150-164.

130. Kandasamy K, Mohan SS, Raju R, Keerthikumar S, Kumar GS, Venugopal AK, Telikicherla D, Navarro JD, Mathivanan S, Pecquet C, et al: NetPath: a public resource of curated signal transduction pathways. Genome Biol 2010, $11: R 3$

131. Ruepp A, Waegele B, Lechner M, Brauner B, Dunger-Kaltenbach I, Fobo G, Frishman G, Montrone C, Mewes HW: CORUM: the comprehensive resource of mammalian protein complexes-2009. Nucleic Acids Res 2010, 38:D497-501.

doi:10.1186/1742-4690-10-160

Cite this article as: Bernier et al:: Transcriptional profiling reveals molecular signatures associated with HIV permissiveness in Th1Th17 cells and identifies Peroxisome Proliferator-Activated Receptor Gamma as an intrinsic negative regulator of viral replication. Retrovirology 2013 10:160 